\title{
Article \\ Protective Effect of Baicalin against Clostridioides difficile Infection in Mice
}

\author{
Abraham Joseph Pellissery ${ }^{1}$, Poonam Gopika Vinayamohan ${ }^{2}$, Deepa Ashwarya Kuttappan ${ }^{1}$, Neha Mishra ${ }^{3}$, \\ Breno de Oliveira Fragomeni ${ }^{1}$, Kendra Maas ${ }^{4}$, Shankumar Mooyottu ${ }^{5}$ and Kumar Venkitanarayanan ${ }^{1, *}$ \\ 1 Department of Animal Science, University of Connecticut, Storrs, CT 06269, USA; \\ abraham.pellissery@uconn.edu (A.J.P.); deepa.kuttappan@uconn.edu (D.A.K.); \\ breno.fragomeni@uconn.edu (B.O.F.) \\ 2 Department of Veterinary Preventive Medicine, Ohio State University, Columbus, OH 43210, USA; \\ vinayamohan.1@osu.edu \\ 3 Department of Pathobiology and Veterinary Science, University of Connecticut, Storrs, CT 06269, USA; \\ neha.mishra@uconn.edu \\ 4 Microbial Analysis, Resources, and Services, University of Connecticut, Storrs, CT 06269, USA; \\ kendra.maas@uconn.edu \\ 5 Department of Veterinary Pathology, Iowa State University, Ames, IA 50011, USA; shaan@iastate.edu \\ * Correspondence: kumar.venkitanarayanan@uconn.edu; Tel.: +1-(860)-486-1957
}

check for updates

Citation: Pellissery, A.J.;

Vinayamohan, P.G.; Kuttappan, D.A.;

Mishra, N.; Fragomeni, B.O.; Maas,

K.; Mooyottu, S.; Venkitanarayanan,

K. Protective Effect of Baicalin against Clostridioides difficile Infection in Mice. Antibiotics 2021, 10, 926. https:// doi.org/10.3390/antibiotics10080926

Academic Editors: Guido Granata and Seok-Hoon Jeong

Received: 15 May 2021

Accepted: 27 July 2021

Published: 30 July 2021

Publisher's Note: MDPI stays neutral with regard to jurisdictional claims in published maps and institutional affiliations.

Copyright: (c) 2021 by the authors. Licensee MDPI, Basel, Switzerland. This article is an open access article distributed under the terms and conditions of the Creative Commons Attribution (CC BY) license (https:/ / creativecommons.org/licenses/by/ $4.0 /)$.

\begin{abstract}
This study investigated the prophylactic and therapeutic efficacies of baicalin (BC), a plant-derived flavone glycoside, in reducing the severity of Clostridioides difficile infection (CDI) in a mouse model. In the prophylactic trial, C57BL/ 6 mice were provided with $\mathrm{BC}(0,11$, and $22 \mathrm{mg} / \mathrm{L}$ in drinking water) from 12 days before $C$. difficile challenge through the end of the experiment, whereas $B C$ administration started day 1 post challenge in the therapeutic trial. Both challenge and control groups were infected with $10^{6} \mathrm{CFU} / \mathrm{mL}$ of hypervirulent $C$. difficile BAA 1803 spores or sterile PBS, and the clinical and diarrheal scores were recorded for 10 days post challenge. On day 2 post challenge, fecal and tissue samples were collected from mice prophylactically administered with BC for microbiome and histopathologic analysis. Both prophylactic and therapeutic supplementation of BC significantly reduced the severity of colonic lesions and improved CDI clinical progression and outcome compared with control $(p<0.05)$. Microbiome analysis revealed a significant increase in Gammaproteobacteria and reduction in the abundance of protective microbiota (Firmicutes) in antibiotic-treated and C. difficile-infected mice compared with controls $(p<0.05)$. However, baicalin supplementation favorably altered the microbiome composition, as revealed by an increased abundance in beneficial bacteria, especially Lachnospiraceae and Akkermansia. Our results warrant follow-up investigations on the use of $\mathrm{BC}$ as an adjunct to antibiotic therapy to control gut dysbiosis and reduce $C$. difficile infection in humans.
\end{abstract}

Keywords: Clostridioides difficile; baicalin; microbiome; gut dysbiosis; mouse model

\section{Introduction}

Clostridioides difficile is an important cause of nosocomial, antibiotic-associated diarrhea around the world [1,2]. The pathogen causes a toxin-mediated colitis in individuals of all age groups, with more severity observed in elderly and immunocompromised patients [3]. In the United States, more than 453,000 cases of C. difficile infection (CDI) with 29,000 deaths are reported annually, which incur an economic burden ranging between USD 0.4 to 3.0 billion as healthcare-associated costs $[4,5]$. The increased incidence of CDI in humans is primarily attributed to the emergence of NAP1/ribotype 027 , a highly toxigenic and hypervirulent $C$. difficile strain [1,6-8].

Generally, individuals requiring long-term antibiotic therapy and gastric acid suppressing agents are highly predisposed to CDI [9-11]. Broad-spectrum antibiotics and acid suppressants alter the diversity and abundance of the normal gut microbial communities, 
resulting in a condition known as gut dysbiosis [12-15]. The dysbiotic gut environment facilitates $C$. difficile spore germination, outgrowth, colonization, and toxin productions in the distal gut [16]. C. difficile exotoxins-namely, toxin A and toxin B-disrupt the actin cytoskeleton and interepithelial tight junctions of the colonic epithelium, leading to severe diarrhea and suppurative inflammation that could culminate in pseudomembranous colitis and toxic megacolon in extreme cases $[1,8,17,18]$.

Although extended antibiotic therapy predisposes individuals to CDI, antibiotics are still considered as the primary line of treatment for this disease, and the most commonly prescribed drugs include metronidazole, vancomycin, and fidaxomicin $[4,7,19,20]$. However, $C$. difficile has been continuously acquiring resistance to different classes of antibiotics, including those currently in clinical use against CDI $[7,21]$. With global emergence of antibiotic resistant and hypervirulent $C$. difficile strains, the Centers for Disease Control and Prevention (CDC) categorized the pathogen a few years ago as one among the three urgent threats to public health [22]. Therefore, there is an emergent need to identify alternative therapeutic agents that could reduce $C$. difficile virulence without adversely affecting the gut microbiota.

Phytochemicals represent a natural group of molecules that have been used for treating various diseases in traditional medicine [23]. Baicalin (5,6-dihydroxy-7-O-glucuronide flavone) is a flavone glycoside present in the plant Scutellaria baicalensis Georgi, known to possess antimicrobial, antioxidant, and anti-inflammatory properties [24-30]. Previously, our laboratory demonstrated the use of baicalin as a potential anti-C. difficile therapeutic agent owing to its inhibitory effect on $C$. difficile toxin production with minimal effects on the growth of selected beneficial microbiota in vitro [31]. As a logical next step, this study investigated the prophylactic and therapeutic effects of baicalin against CDI in an in vivo model by focusing on the clinical course and host microbiome changes in mice. Mouse models for CDI are well established, and antibiotic-induced gut dysbiosis in mice can be simulated by administering antibiotics orally and intraperitoneally, followed by inoculation of $C$. difficile spores $[32,33]$.

\section{Results}

\subsection{Effect of Baicalin Supplementation on the Incidence of Diarrhea and Severity of C. difficile} Infection in Mice

The prophylactic efficacy of baicalin against CDI in mice was assessed by supplementing the phytochemical in drinking water at two different concentrations (11 and $22 \mathrm{mg} / \mathrm{L}$ ). Oral administration of $10^{6} \mathrm{CFU} / \mathrm{mL}$ C. difficile spores (ATCC BAA 1803) resulted in high morbidity with low mortality in infected mice. In C. difficile-infected control groups (CD), $61 \%$ and $85 \%$ of animals showed severe diarrhea on the first- and second-day post infection (DPI) $(n=13)$, respectively (Figure 1a). On 7 DPI, one animal from the CD group died, and no further mortality was recorded in this group (Supplementary Figure S3a). Although diarrhea continued for five days in the $\mathrm{CD}$ group, there was no increase in the percentage incidence of diarrhea thereafter (data not shown). However, the incidence of diarrhea was significantly lower in the $\mathrm{CD}+\mathrm{BC} 1$ (challenged mice treated with $11 \mathrm{mg} / \mathrm{L}$ of $\mathrm{BC}$ ) group, with $38 \%$ and $31 \%$ incidence on 1 DPI and 2 DPI, respectively, and with the absence of diarrhea on the subsequent days (Figure 1a). Moreover, diarrhea was not observed in the $\mathrm{CD}+\mathrm{BC} 2$ group (challenged mice treated with $22 \mathrm{mg} / \mathrm{L}$ of $\mathrm{BC})(p<0.05)$, although there were two mortalities recorded in this group, one each on days 2 and 3 post infection (Supplementary Figure S3a). 

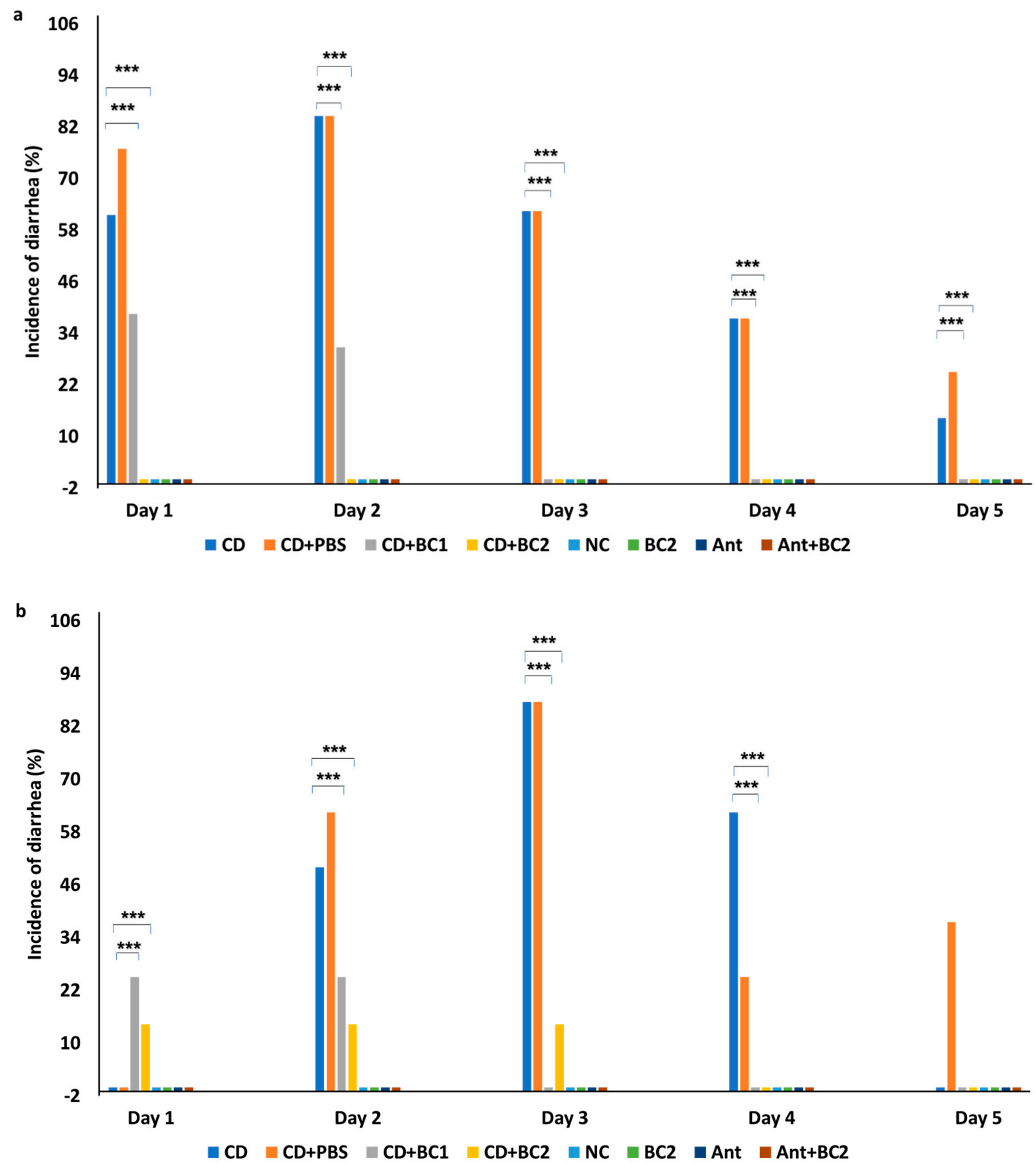

Figure 1. Effect of baicalin supplementation on the incidence of diarrhea in mice after CDI. Percentage incidence of diarrhea was recorded from 1 DPI to 5 DPI in the different treatment groups in the prophylactic BC study (a) therapeutic BC study (b). ${ }^{* * *}$ indicates a statistically significant difference $(p<0.0001)$ relative to challenged, positive control $(C D)$ vs. the baicalin-treated challenged mice $(\mathrm{CD}+\mathrm{BC} 1$ or $\mathrm{CD}+\mathrm{BC} 2)$. Error bars represent SEM. Treatment groups: NC (unchallenged negative control), Ant (unchallenged antibiotic control), Ant+BC (unchallenged antibiotic $+22 \mathrm{mg} / \mathrm{L} \mathrm{BC}$ control), BC2 (unchallenged $22 \mathrm{mg} / \mathrm{L} \mathrm{BC}$ control), CD (Ant+C. difficile-challenged control), CD+PBS (Ant+C. difficile-challenged control, PBS solvent control), CD+BC1 (Ant+ CD + $11 \mathrm{mg} / \mathrm{L} \mathrm{BC}), \mathrm{CD}+\mathrm{BC} 2(\mathrm{Ant}+\mathrm{CD}+22 \mathrm{mg} / \mathrm{L} \mathrm{BC})$.

In the therapeutic trial, baicalin was supplemented in drinking water similar to the prophylactic trial but was initiated from day 1 post challenge. Interestingly, the $C$. difficile positive control group (Ant+CD) did not show any diarrhea on 1 DPI; however, diarrhea was observed in $62.5 \%$ and $87.5 \%$ animals on 2 DPI $(n=13)$ and 3 DPI $(n=5)$, respectively (Figure 1b). Diarrhea was observed until the fifth day post infection in this group, with no additional increase in percentage incidence after 3 DPI. Diarrhea was observed from 
$1 \mathrm{DPI}$ in the $\mathrm{CD}+\mathrm{BC} 1$ and $\mathrm{CD}+\mathrm{BC} 2$ groups, although a significantly reduced incidence was observed for both BC-treated groups compared with the positive control $(p<0.05)$. An incidence of $25 \%$ was observed on both 2 DPI and 3 DPI in CD+BC1 group, with no diarrhea thereafter. In the $\mathrm{CD}+\mathrm{BC} 2$ group, the incidence of diarrhea stayed at $14 \%$ for days 1-3 post infection, with no more diarrhea observed for the remainder of experiment duration (Figure $1 \mathrm{~b}$ ). In addition, there was only one mortality recorded in the C. difficilepositive control group on 6 DPI (Supplementary Figure S3b).

No diarrhea was observed in the control groups (i.e., negative control (NC), baicalin control (BC2), antibiotic control (Ant), and antibiotic with baicalin control (Ant+BC2)) in both the prophylactic and therapeutic BC studies.

\subsection{Effect of Baicalin Supplementation on Clinical Score and Body Weight of C. difficile-Infected Mice}

Clinical scores of animals from different treatment groups were individually recorded using a standard score chart, from 1 DPI to 10 DPI (Supplementary Table S1) (Chen et al., 2008). Groups receiving prophylactic supplementation of baicalin (CD+BC1 and $C D+B C 2)$ had a significantly reduced average clinical score compared with the challenge control (CD) $(p<0.05)$ (Figure 2a). The recovery of surviving morbid animals in the $C$. difficile control group was much slower compared with baicalin-treated groups $(p<0.05)$, with apparent clinical resolution observed by 9 DPI. However, the baicalin-supplemented groups showed a dose-dependent reduction in disease severity, with complete recovery observed by 6 DPI $(p<0.05)$. Although not statistically significant, the clinical score of the $\mathrm{CD}+\mathrm{BC} 2$ group was lower compared with that of $\mathrm{CD}+\mathrm{BC} 1$ group. Interestingly, a similar trend in the average clinical scores was also observed in the baicalin therapeutic trial. The clinical scores in $\mathrm{CD}+\mathrm{BC} 1$ and $\mathrm{CD}+\mathrm{BC} 2$ groups also followed a dose-dependent reduction in disease severity (Figure $2 \mathrm{~b}$ ). However, the recovery rate was much slower compared with the prophylactic study, where no complete resolution of clinical disease was observed until the end of the experiment (day 10 post- $C$. difficile challenge).

Body weights were recorded on a daily basis post infection, and the relative percentage weight with respect to the initial weight prior to the $C$. difficile challenge was calculated. In the prophylactic study, the baicalin control group (BC2) and Ant+BC2 group showed no significant weight loss compared with negative control. However, mice in the $C$. difficile-positive control (CD) showed a significant and progressive weight loss from 1 DPI to 5 DPI compared with unchallenged control $(p<0.05)$, with animals regaining their pre-challenge body weights by 9 DPI. Although there was no significant difference in the average body weights of mice from the $B C$-treated challenge groups $(C D+B C 1$ and $\mathrm{CD}+\mathrm{BC} 2$ ) compared with positive control, baicalin-treated animals were able to rapidly regain their pre-challenge body weights by 5 DPI compared with the $C$. difficile-positive control (9 DPI) (Figure 2c).

In the therapeutic trial, $C$. difficile-challenge control (CD) showed significant weight loss compared with negative controls $(p<0.05)$. Mice in the $C$. difficile-challenge control group showed progressive weight reduction 3 DPI through 6 DPI, returning to their initial body weights by 8 DPI. In addition, there was no significant difference in average percentage body weights between the $\mathrm{CD}$ group and $\mathrm{CD}+\mathrm{BC} 1$ group. However, a significant difference was observed in the average percentage body weights of the $C D+B C 2$ groups compared with the CD group on days 3 and 4 post challenge $(p<0.05)$ (Figure 2d). Moreover, the $\mathrm{CD}+\mathrm{BC} 2$ group attained their pre-challenge body weight by $4 \mathrm{DPI}$; however, a slight delay was observed in the $\mathrm{CD}+\mathrm{BC} 1$ group, with animals attaining their initial body weight by 6 DPI (Figure 2d). 

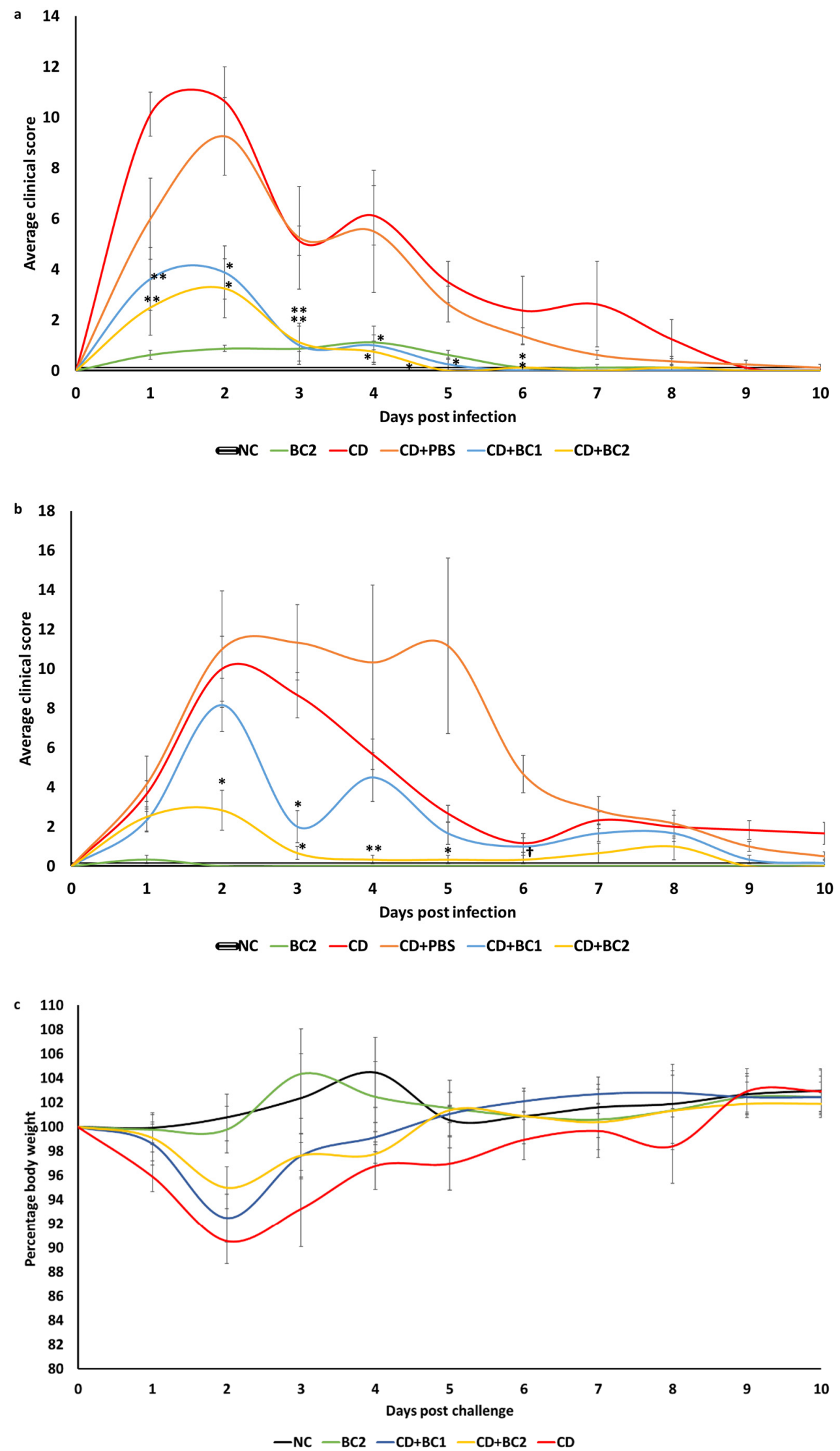

Figure 2. Cont. 


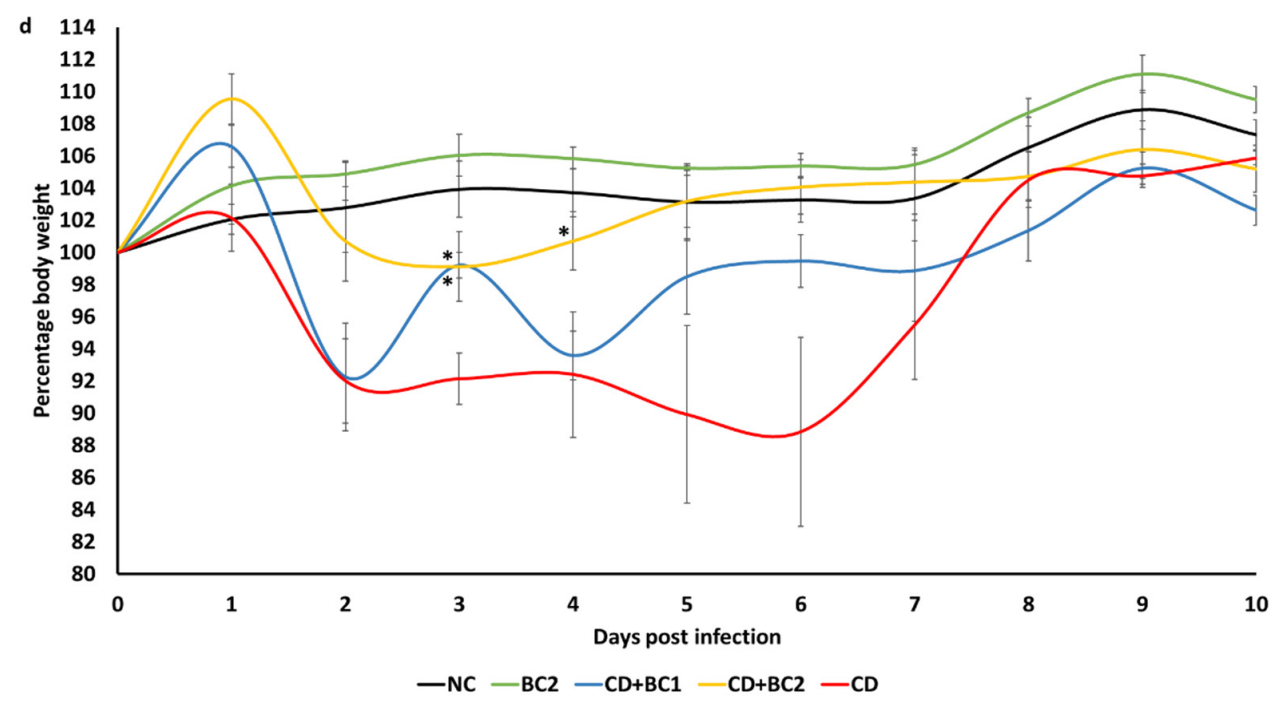

Figure 2. Effect of baicalin supplementation on clinical severity and change in body weight in mice after CDI. Average clinical scores and percentage body weights were recorded from 1 DPI to 10 DPI for the different treatment groups in the prophylactic BC study $(\mathbf{a}, \mathbf{c})$ and therapeutic BC study $(\mathbf{b}, \mathbf{d}) .{ }^{* *},{ }^{*}$ indicates a statistically significant difference $(p<0.001$, $p<0.05$, respectively) relative to the untreated challenge group (CD); + symbol indicates a statistically significant difference $(p<0.05)$ relative to CD+PBS. Percentage body weights among treatment groups (in $(\mathrm{c}, \mathrm{d})$ were compared within the same day time point. Error bars represent SEM. Treatment groups: NC (unchallenged negative control), Ant (unchallenged antibiotic control), Ant+BC (unchallenged antibiotic $+22 \mathrm{mg} / \mathrm{L} \mathrm{BC}$ control), BC2 (unchallenged $22 \mathrm{mg} / \mathrm{L} \mathrm{BC} \mathrm{control),} \mathrm{CD}$ $($ Ant $+C$. difficile-challenged control), $\mathrm{CD}+\mathrm{PBS}(\mathrm{Ant}+\mathrm{C}$. difficile-challenged control, PBS solvent control), $\mathrm{CD}+\mathrm{BC} 1(\mathrm{Ant}+\mathrm{CD}+$ $11 \mathrm{mg} / \mathrm{L} \mathrm{BC}), \mathrm{CD}+\mathrm{BC} 2(\mathrm{Ant}+\mathrm{CD}+22 \mathrm{mg} / \mathrm{L} \mathrm{BC})$.

\subsection{Effect of Baicalin Supplementation on the Gut Microbiome of C. difficile-Challenged and Non-Challenged Mice}

The results from the prophylactic trial revealed distinctive patterns in the composition of bacterial communities in the different treatment groups. In the unchallenged control group (NC), the predominant phyla groups consisted of Firmicutes and Bacteroidetes in a ratio of 1.05:1, with a minimal proportion of other taxa related to opportunistic pathogens such as Gammaproteobacteria and Enterococcaceae (Figure 3a). In the baicalin control group (BC2), a higher proportion of Firmicutes was observed, compared with Bacteroidetes having a ratio of 1.79:1. Although, the phyla comparisons seemingly had a greater degree of difference in their proportion across groups, it was statistically insignificant. The antibiotic control group (Ant) had a higher proportion of Gammaproteobacteria and Enterococcaceae compared with the negative control and baicalin control group. The supplementation of baicalin along with the antibiotic (Ant+BC2) seemed to reduce the proportion of Enterococcaceae but was not able to reverse the increase in Gammaproteobacteria. However, there was an increase in the proportion of the phylum Verrucomicrobia (represented as genus Akkermansia) compared with the antibiotic control group (Figure 3a). The baicalin untreated challenge groups (CD and $C D+P B S$ ) had a predominantly higher proportion of Firmicutes and Gammaproteobacteria compared with uninfected controls. However, baicalin administration to $C$. difficile-challenged groups $(C D+B C 1$ and $C D+B C 2)$ reduced the abundance of Firmicutes and increased the proportion of Proteobacteria compared with the antibiotic control and positive control groups (CD and CD+PBS). A notably distinct phylum that prevailed among baicalin-treated, spore-challenged (CD+BC1 and CD+BC2), and unchallenged (BC2 and Ant+BC2) groups was Verrucomicrobia, specifically the genus Akkermansia (Figure 3a). 


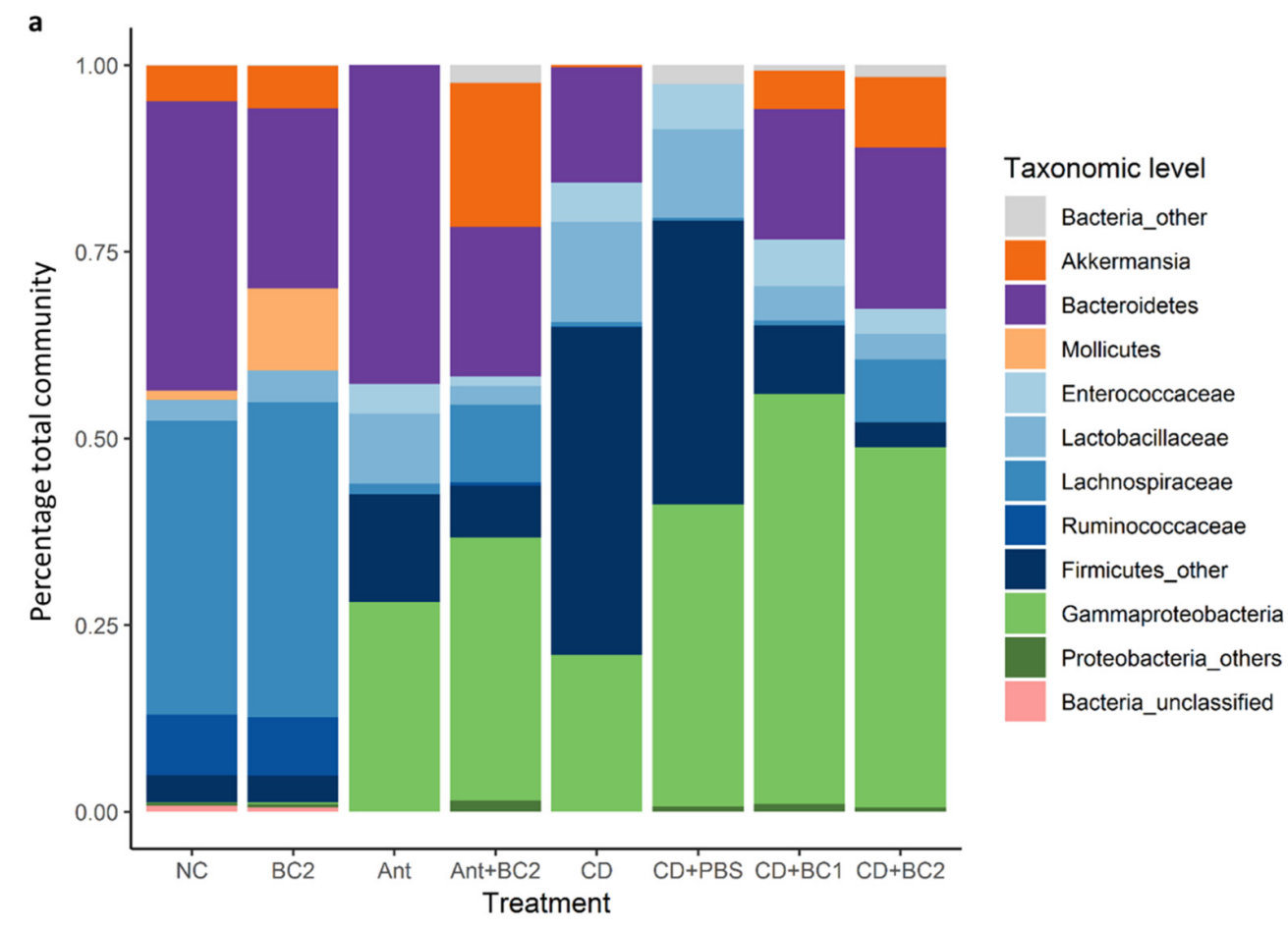

b
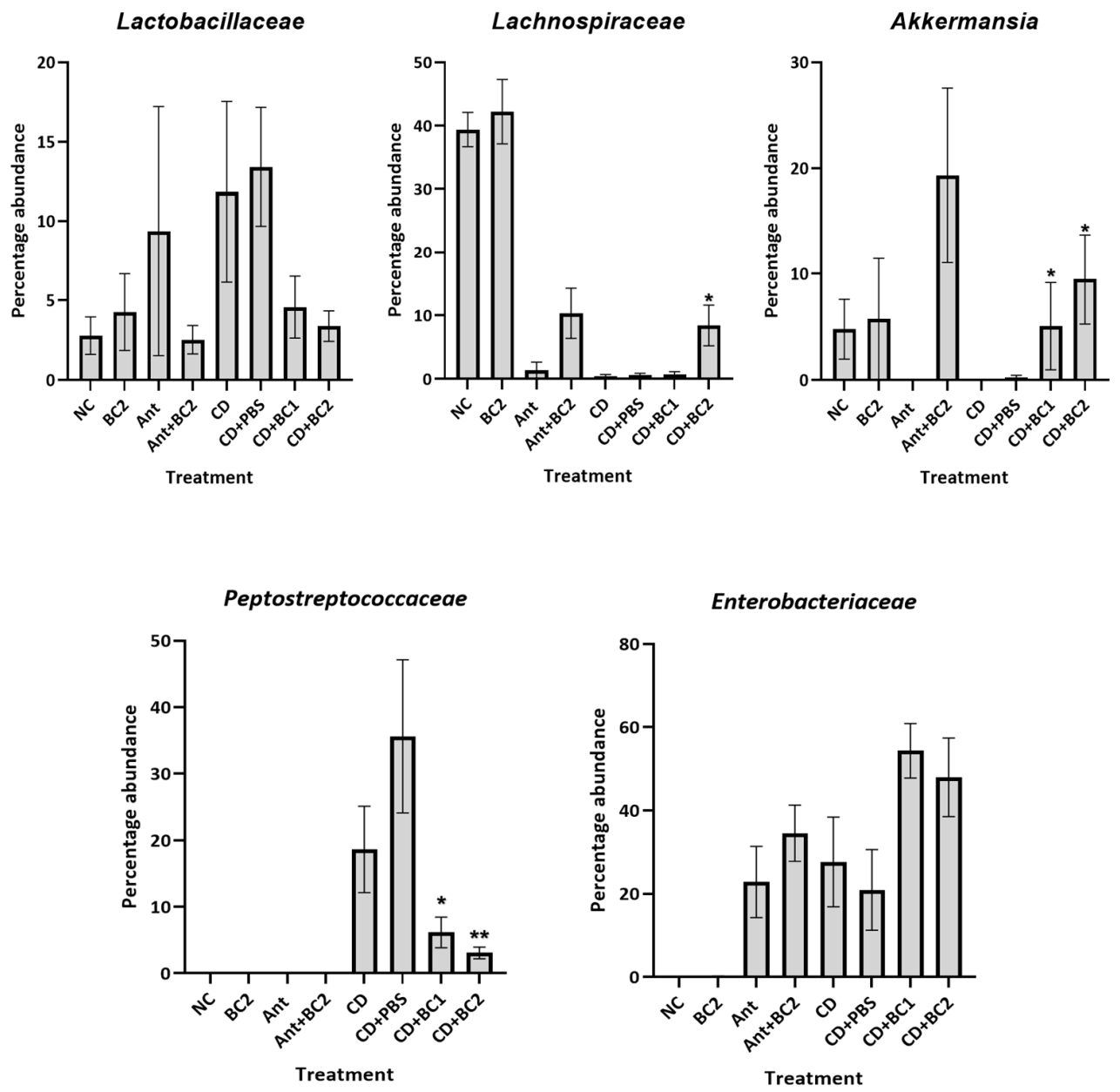

Figure 3. Cont. 

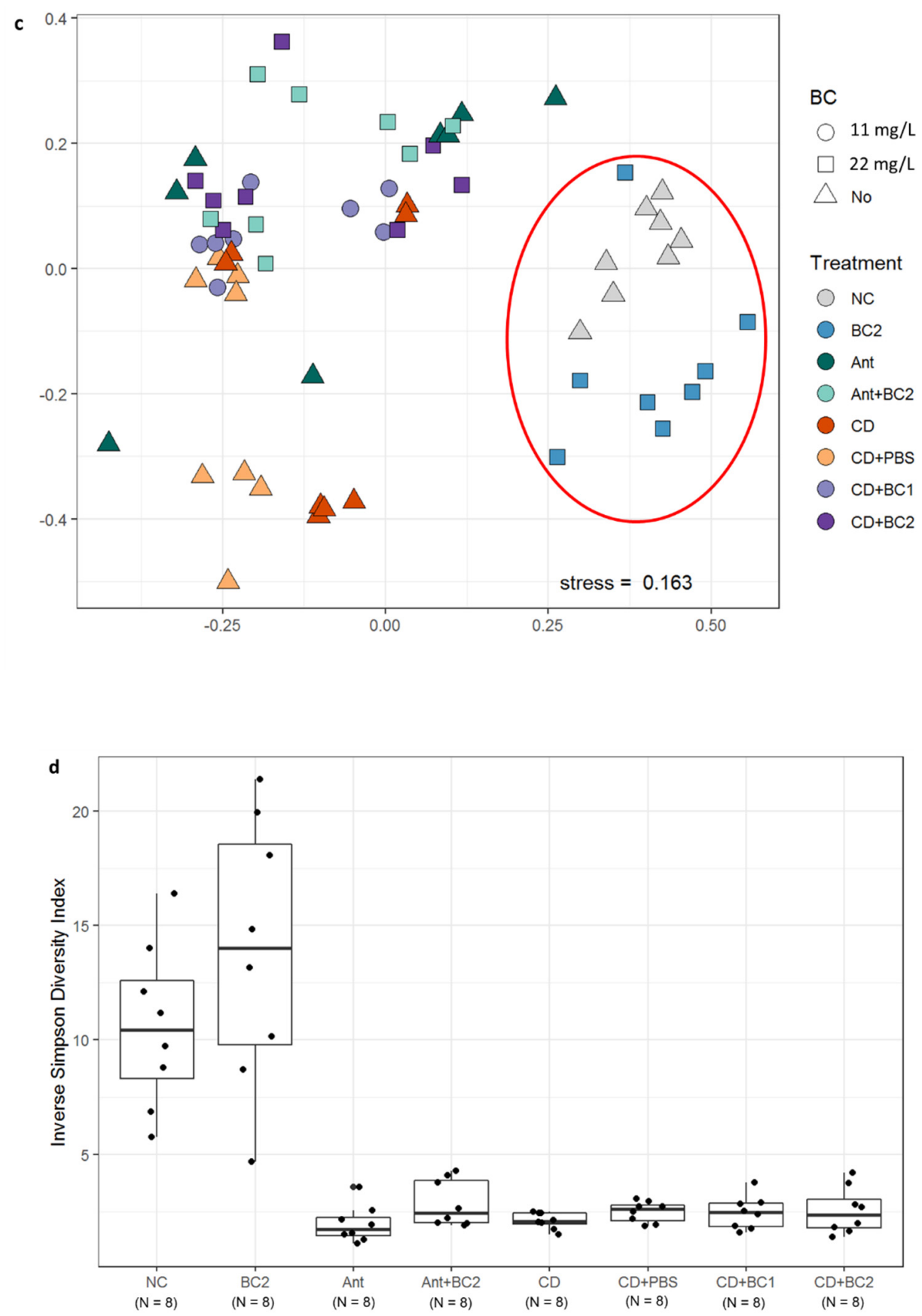

Figure 3. Effect of baicalin supplementation on the abundance of major gut microbiome taxa and microbiome diversity in the antibiotic-treated and C. difficile-challenged mice. (a) Relative taxa abundance of OTUs: Fecal samples were collected 2 DPI from the prophylactic BC study. DNA was extracted for microbiome analysis using Illumina MiSeq platform, and the relative abundance of OTUs of major phyla, order, family, and genera was determined. (b) Abundance of major bacterial family taxa. Percentage abundances of major families-Lactobacillaceae, Lachnospriaceae, Akkermansia, Peptostreptococcaceae, and Enterobacteriaceae - in the mice treatment groups of the prophylactic BC study. ${ }^{* *},{ }^{*}$ indicates a statistically significant difference ( $p<0.001, p<0.05$, respectively) relative to the untreated challenge group (CD). Error bars represent SEM. (c) Bray-Curtis plot: Relationships between treatment groups based on the abundance of species present in each sample were plotted. NMS ordinations were run in R (v 3.3.0) using metaMDS in the vegan (v 2.3-5) package after calculating the stress scree plots to determine the number of axes required to achieve stress below 0.2, plotted using ggplot2 (v 2.1.0). (d) Inverse Simpson Plot: Fecal samples were collected 2 DPI of the prophylactic BC study. DNA was extracted for microbiome analysis 
using Illumina MiSeq platform, and Alpha diversity was calculated using inverse Simpson to measure the richness and evenness of the OTUs. Treatment groups: NC (unchallenged negative control), Ant (unchallenged antibiotic control), Ant+BC (unchallenged antibiotic $+22 \mathrm{mg} / \mathrm{L} \mathrm{BC}$ control), BC2 (unchallenged $22 \mathrm{mg} / \mathrm{L} \mathrm{BC}$ control), CD (Ant $+C$. difficilechallenged control), CD+PBS (Ant+C. difficile-challenged control, PBS solvent control), CD+BC1 (Ant+CD + $11 \mathrm{mg} / \mathrm{L} \mathrm{BC}$ ), $\mathrm{CD}+\mathrm{BC} 2(\mathrm{Ant}+\mathrm{CD}+22 \mathrm{mg} / \mathrm{L} \mathrm{BC})$.

At the family/genus level, the relative abundance of Lactobacillaceae did not show any significant difference amongst the negative control (NC), baicalin control (BC2), and baicalin-treated antibiotic control groups (Ant+BC2) $(p>0.05)$. In contrast, the antibiotic control and untreated spore challenge groups (CD and CD+PBS) had a higher abundance of Lactobacillaceae compared with the aforementioned controls; however, it was not statistically significant. However, although not significant, baicalin-treated spore challenge groups had a much lower abundance of Lactobacillaceae compared with positive controls (Figure 3b). With regards to Lachnospiraceae and Akkermansia, although not significant, baicalin-treated control (BC2) marginally increased their relative abundance compared with the negative control $(p>0.05)$ (Figure $3 b)$. In untreated spore challenge groups (CD and CD+PBS), the abundance of both Lachnospiraceae and Akkermansia was significantly reduced compared with the negative control (NC), baicalin control (BC2), and the baicalin-treated antibiotic control (Ant+BC2) $(p<0.05)$. However, with the exception of the $\mathrm{CD}+\mathrm{BC} 1$ group, there was a significant increase in the relative abundance of Lachnospiraceae in the $\mathrm{CD}+\mathrm{BC} 2$ group compared with untreated spore challenge groups (CD and CD+PBS) $(p<0.05)$. In terms of the relative abundance of Akkermansia, there was a significant increase in both baicalin-treated challenge groups compared with untreated spore challenge groups $(p<0.05)$ (Figure 3b). The relative abundance of Peptostreptococcaceae was negligible and showed no significant difference in the negative control (NC), baicalin control (BC2), and antibiotic controls (Ant and Ant+BC2 groups) $(p>0.05)$ (Figure $3 b$ ). However, in baicalin-treated spore-challenged groups $(\mathrm{CD}+\mathrm{BC} 1$ and $\mathrm{CD}+\mathrm{BC} 2)$, Peptostreptococcaceae was significantly reduced compared with the $\mathrm{CD}+\mathrm{PBS}$ group (not $\mathrm{CD}$ group), which had a higher abundance $(p<0.05)$. The abundance of Enterobacteriaceae was higher in antibiotic control (Ant), baicalin-treated antibiotic control group (Ant+BC2), C. difficilepositive control and PBS control (CD and $\mathrm{CD}+\mathrm{PBS}$ ) groups compared with negative control and baicalin control (BC2) groups (Figure $3 b$ ).

The non-metric multi-dimensional scaling (NMDS) plot indicating the differential pattern of bacterial diversity revealed a close clustering of baicalin control (BC2) and negative control, suggesting that the species abundance in the $\mathrm{BC} 2$ group is comparable with the untreated negative control. However, the other treatment groups (antibiotictreated groups, challenged or unchallenged with C. difficile, and with or without BC treatment) did not indicate a typical relationship pattern for the abundance of species present in each sample (Figure 3c). The inverse Simpson plot representing the differential pattern of bacterial diversity revealed that the $\mathrm{BC} 2$ group did not alter the diversity of the gut bacterial community compared with the negative control (NC) $(p>0.05)$. However, irrespective of the baicalin treatment, there was a marked reduction in the diversity of bacterial communities in C. difficile-infected groups and antibiotic controls (Figure 3d).

\subsection{Effect of Baicalin Supplementation on Histopathologic Lesion Score of C. difficile-Infected and Non-Infected Mice}

In both the prophylactic and therapeutic studies, the C. difficile-positive control (CD) and $\mathrm{CD}+\mathrm{PBS}$ group showed significantly severe colitis compared with the unchallenged negative controls $(p<0.0001)$. The representative histopathological slides shown in the figure are from the treatment groups NC (Figure 4a(i)), CD+BC1 (Figure 4a(ii)), CD+BC2 (Figure $4 \mathrm{a}(\mathrm{iii}, \mathrm{iv})$ ), and CD (Figure $4 \mathrm{a}(\mathrm{v}, \mathrm{vi})$ ) and from the histopathological scores for all the treatment groups provided in Figure $4 \mathrm{~b}(\mathrm{i}, \mathrm{ii}))$. The microscopic observations and histopathological scores indicate that the model was a severe disease challenge model, and the positive and negative control treatment groups worked accordingly. 
a

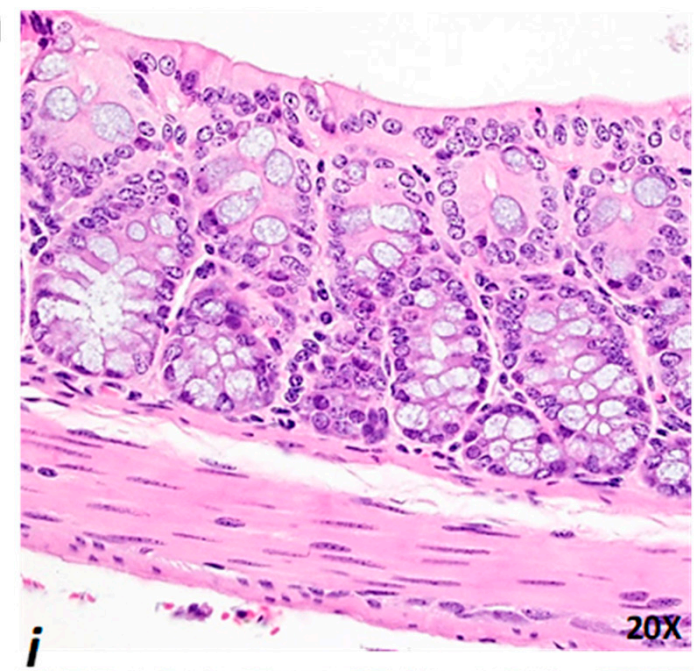

i

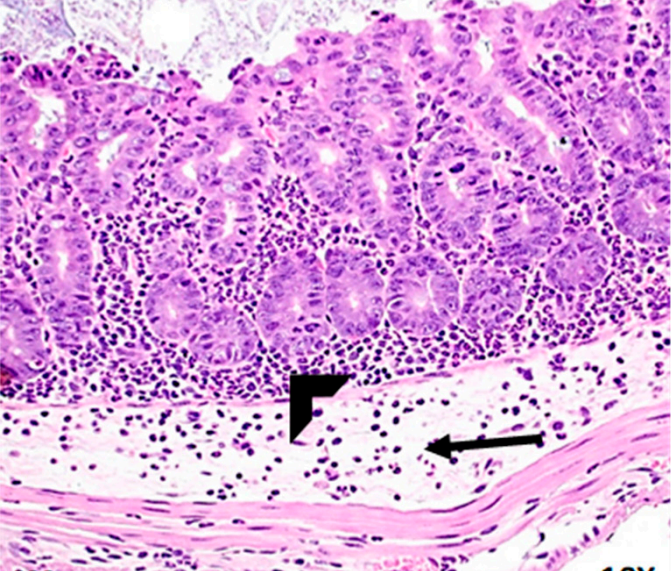

ifi $-2510 \mathrm{x}$

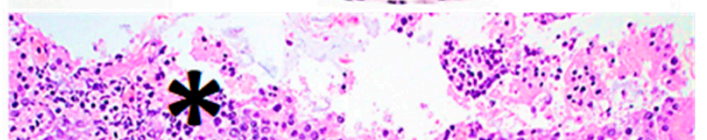

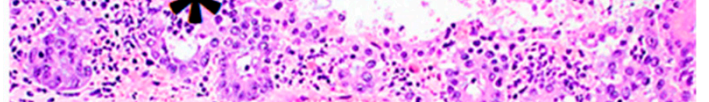
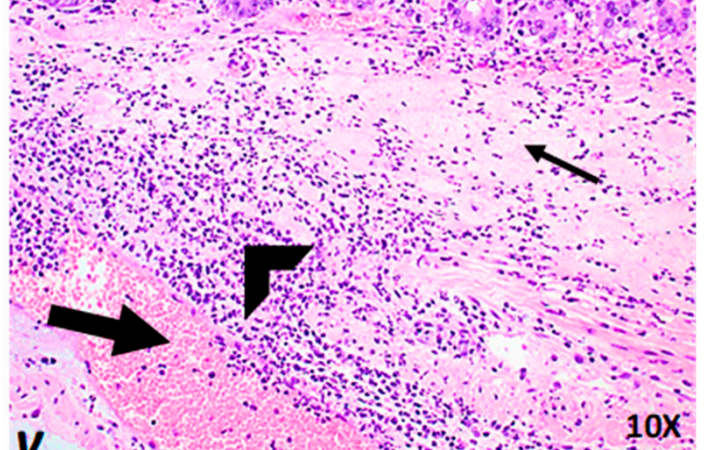

v ne $10 x$
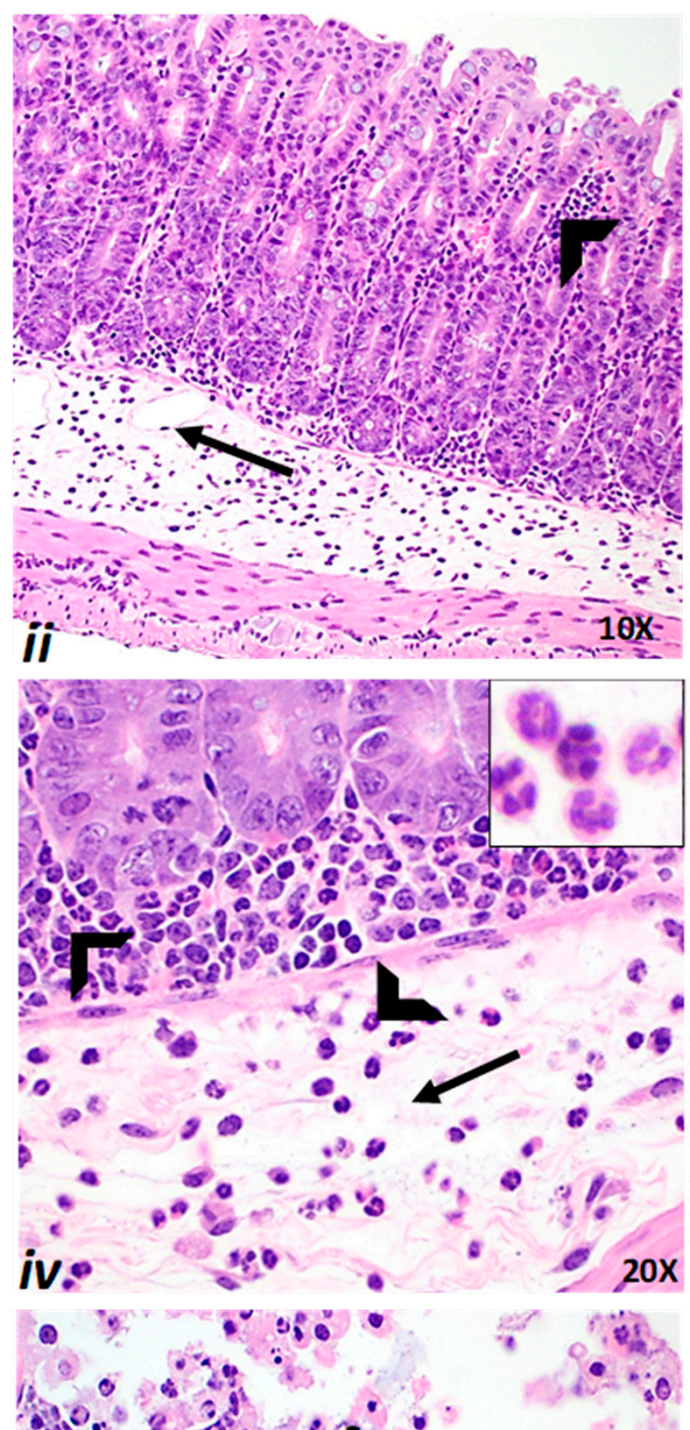

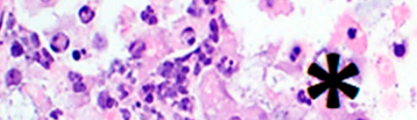

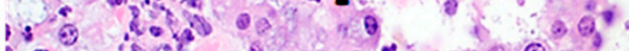

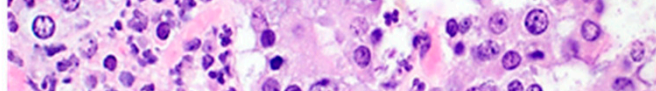

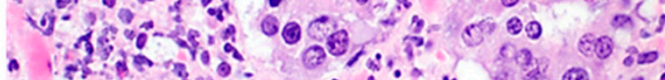

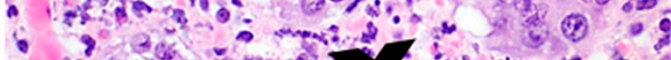

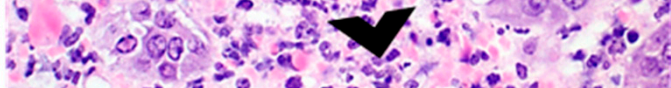

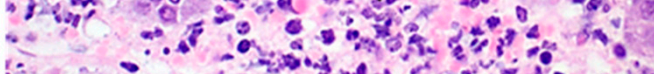

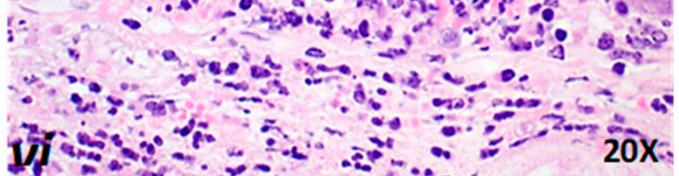

if

Figure 4. Cont. 

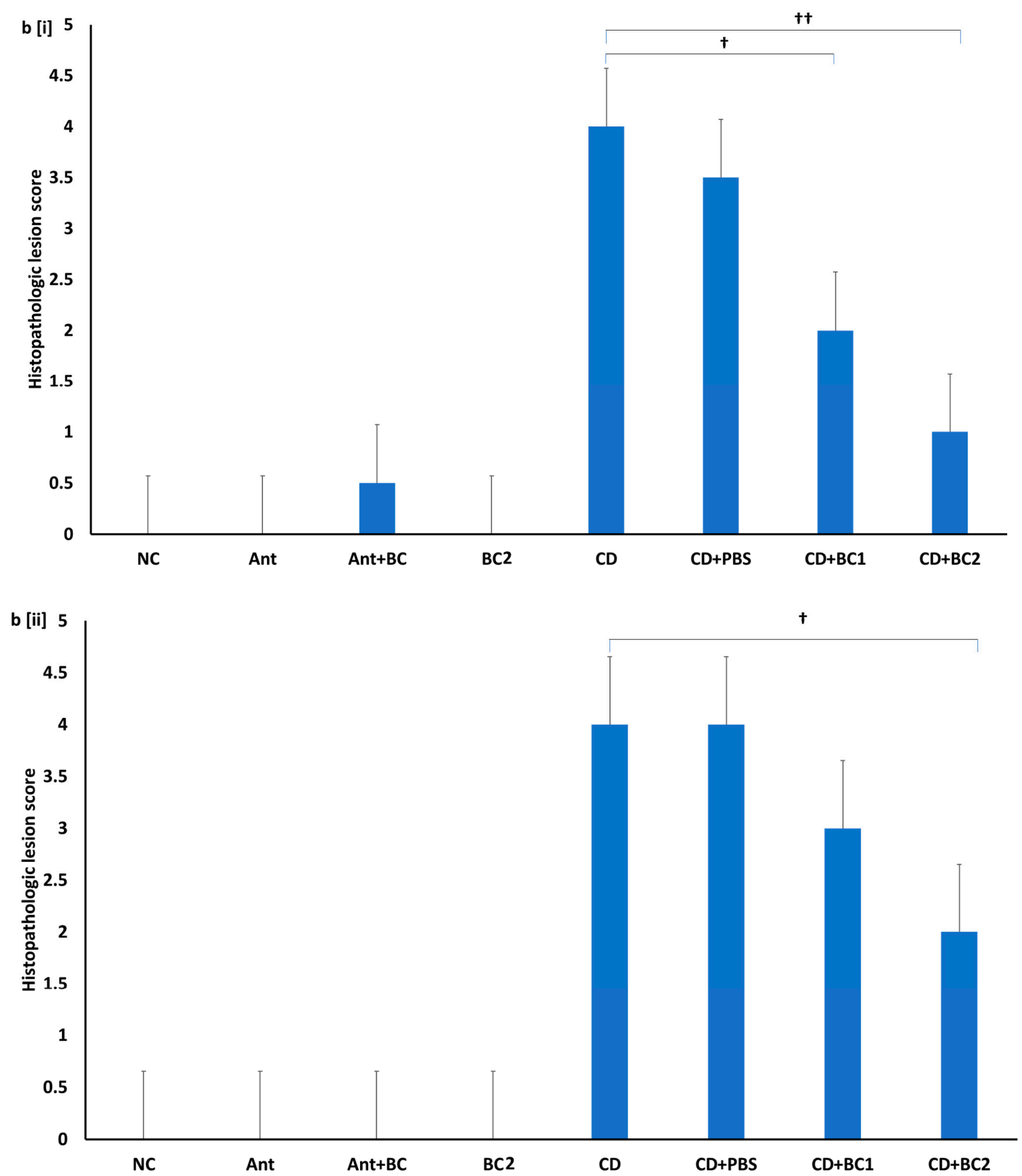

Figure 4. Colon histology and lesion scores. (a) Histologic examination of representative colonic tissues; (i) NC groupnormal colon appearance; (ii) $\mathrm{CD}+\mathrm{BC} 1$ group — colitis with submucosal and lamina propria inflammation (arrowhead) and moderate submucosal edema with dilated lymphatics (arrow); (iii,iv) CD+BC2 group-moderate colitis with submucosal edema (arrow), inflammation composed predominantly of neutrophils (arrowhead), and inset in (iv) shows neutrophils in higher magnifications $(60 \times)$, which are predominantly inflammatory cells observed in the lamina propria and submucosa; (v,vi) CD group—severe colitis with marked submucosal protein-rich edema (arrow) congestion (thick arrow) and hemorrhage, enterocyte necrosis (asterisk) and erosion, and marked neutrophil infiltration (arrowhead). (b) Histopathologic scoring was based on (1) epithelial tissue damage; (2) congestion, edema, and hemorrhage; and (3) neutrophil infiltration. A score of $0-4$ was assigned to each animal, denoting 0 for the absence of lesion, 1 for minimal, 2 for mild, 3 for moderate, and 4 for the severe histopathologic lesion. Mean of individual category scores were calculated to provide an overall histopathologic lesion score for each mouse and then for each group. Error bars represent SEM. (i) Prophylactic study; (ii) therapeutic study. $+\uparrow,+$ symbol indicates a statistically significant difference $(p<0.001, p<0.05$, respectively) relative to challenged, positive control (CD) vs. the baicalin-treated challenged mice (CD+BC1 or $\mathrm{CD}+\mathrm{BC} 2)$. 
Interestingly, mice groups receiving the prophylactic supplementation of baicalin $(\mathrm{CD}+\mathrm{BC} 1$ and $\mathrm{CD}+\mathrm{BC} 2)$ had a significantly reduced histopathologic lesion score compared with C. difficile-positive control (CD) $(p<0.05$ and $p<0.001)$ (Figure 4a(ii-iv),b(i)). However, in the therapeutic study, only high baicalin dose treatment $(\mathrm{CD}+\mathrm{BC} 2)$ had significantly reduced histopathologic lesion score $(p<0.05)$ compared with $C$. difficile-positive control (CD) (Figure $4 \mathrm{~b}(\mathrm{ii})$ ). However, in both study designs, i.e., the prophylactic and therapeutic studies, the higher doses in the $\mathrm{CD}+\mathrm{BC} 2$ group had decreased histopathologic lesions as compared with the low dose $\mathrm{CD}+\mathrm{BC} 1$, although this reduction was not statistically significant.

\subsection{Effect of Baicalin Supplementation on Fecal C. difficile Counts and Fecal Toxin-Mediated Cytotoxicity on Vero Cells}

qPCR-based fecal $C$. difficile counts in the untreated, challenged mice groups, CD and CD+PBS, were 4.25 and $4.10 \log \mathrm{CFU} / \mathrm{mL}$, respectively. However, there was a mild reduction in counts by $\sim 0.5 \log \mathrm{CFU} / \mathrm{mL}$ in both the $\mathrm{CD}+\mathrm{BC} 1$ and $\mathrm{CD}+\mathrm{BC} 2$ treatment groups when compared with the untreated challenged mice groups (Figure 5a(i)). Fecal C. difficile spore enumeration was performed by serial dilution and plating on samples collected from day 4 and 6 post infection. Although there was approximately a 2-log reduction in $C$. difficile spore counts in the day 4 fecal samples of challenged, BC-treated mice compared with the positive control (CD) $(p<0.001)$, the $C$. difficile counts were almost the same level by day 6 post infection $(p>0.05)$ (Figure $5 b(i i, i i i)$ ). In addition, the fecal slurry supernatants from the BC-treated, challenged mice showed a reduction in Vero cell cytotoxicity compared with the untreated, challenged mice. Vero cell cytotoxicity with day 4 and day 6 fecal samples from $C D+B C 1$ and CD+BC2 mice groups showed $96 \%(p<0.05)$ and $99 \%(p<0.05)$, and $64 \%(p=0.18)$ and $96 \%(p<0.05)$ reduction, respectively when compared with the untreated, $C$. difficile-challenged mice (Figure $5 b(\mathrm{i}, \mathrm{ii})$ ).
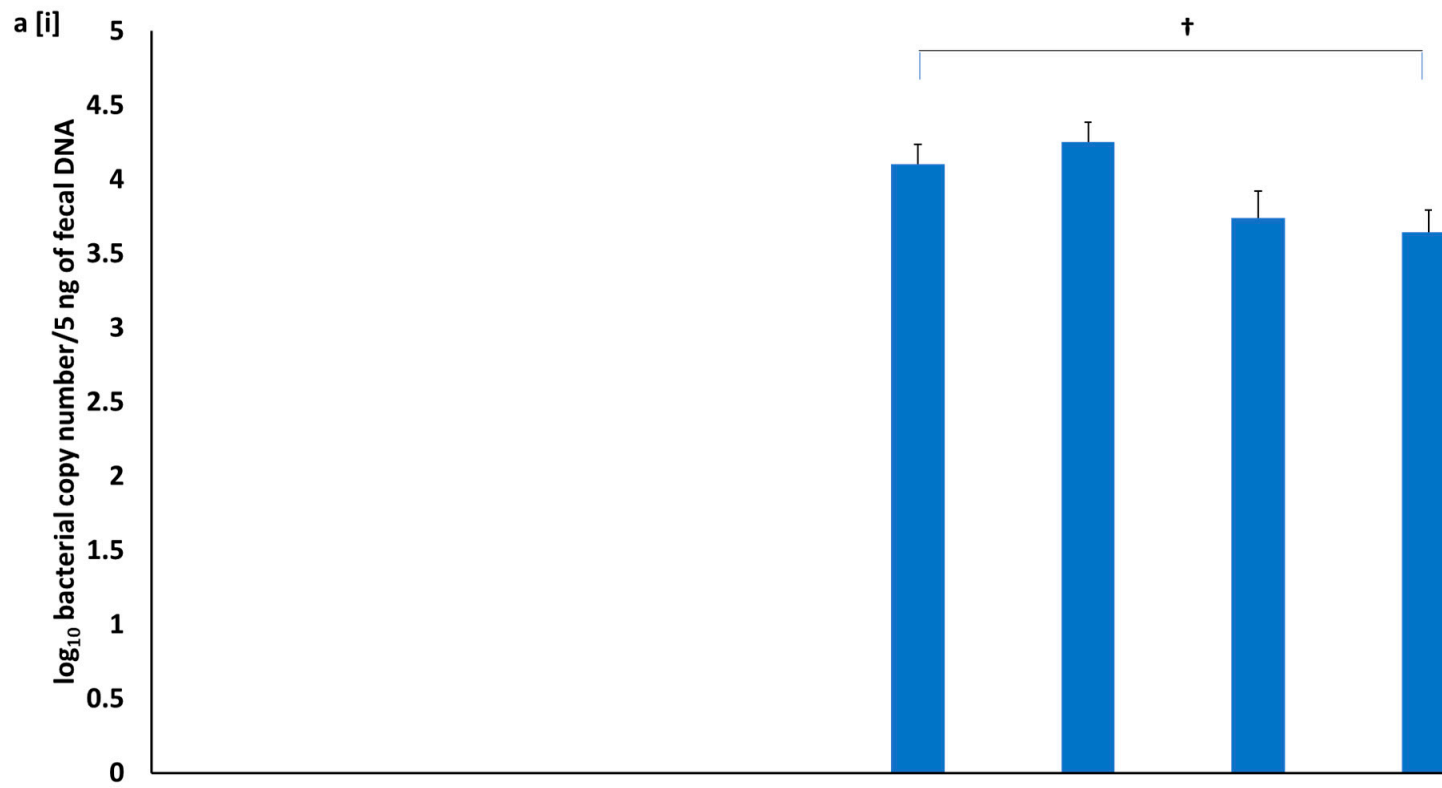

Figure 5. Cont. 


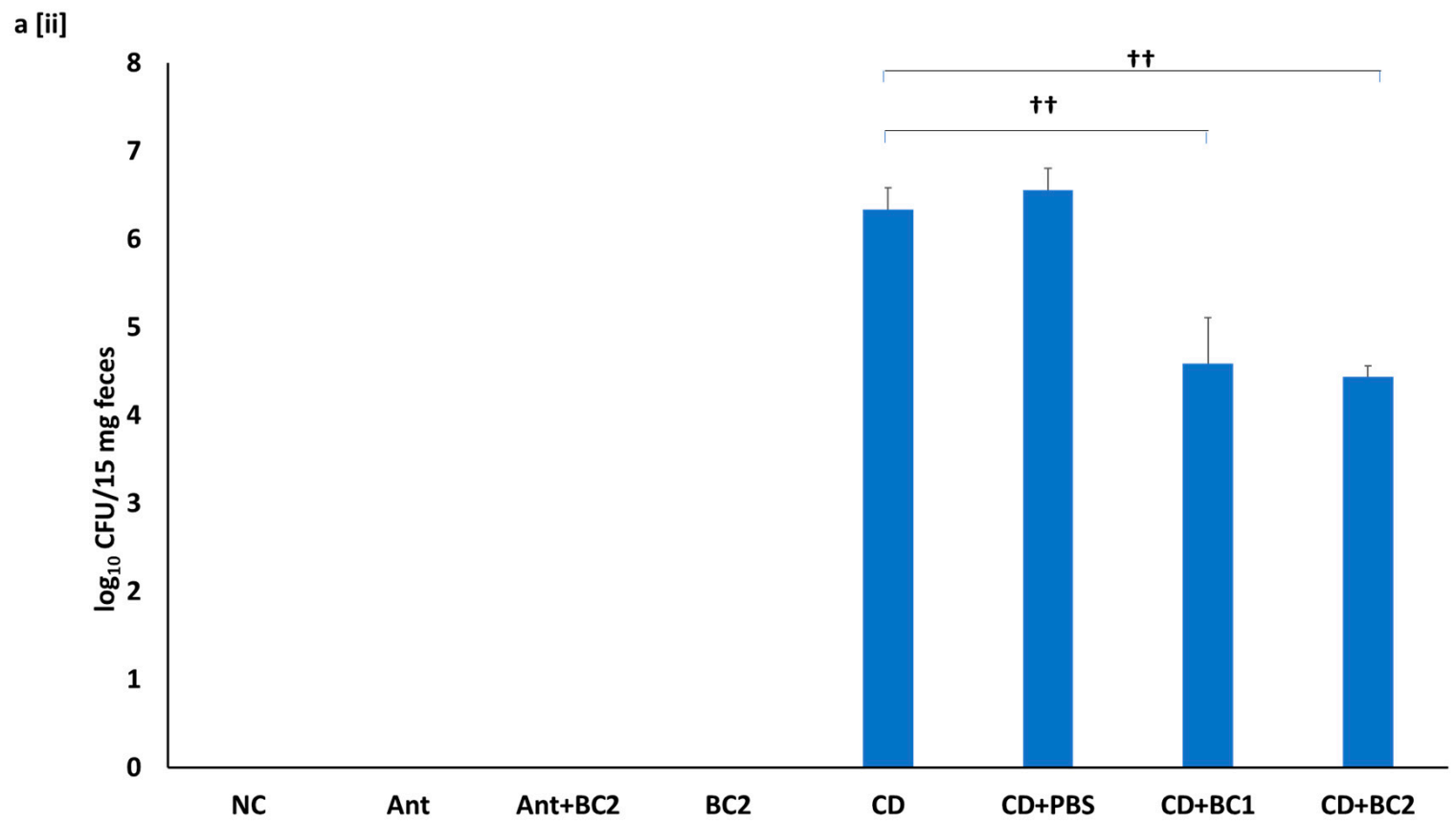

a [iii]

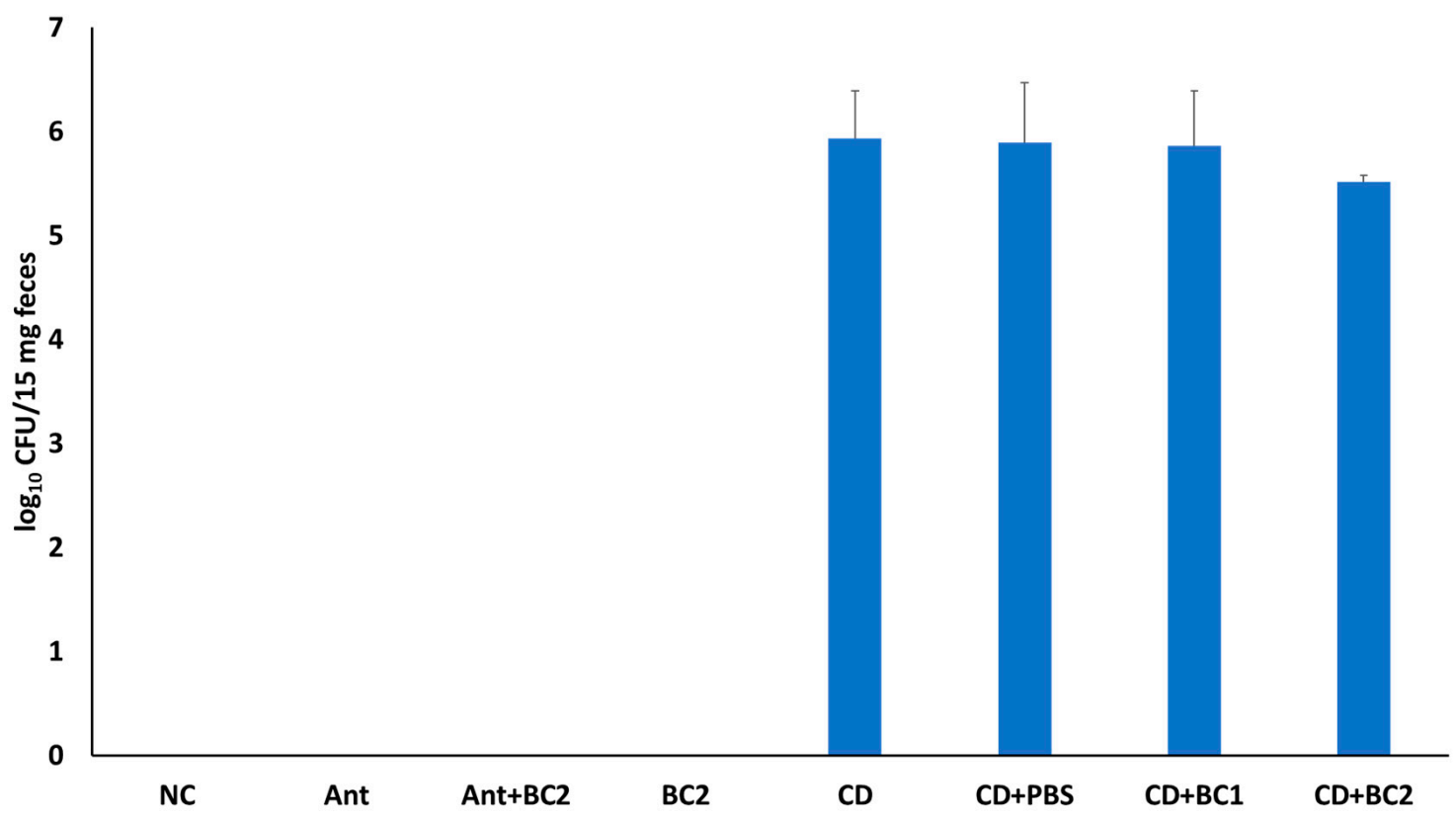

Figure 5. Cont. 


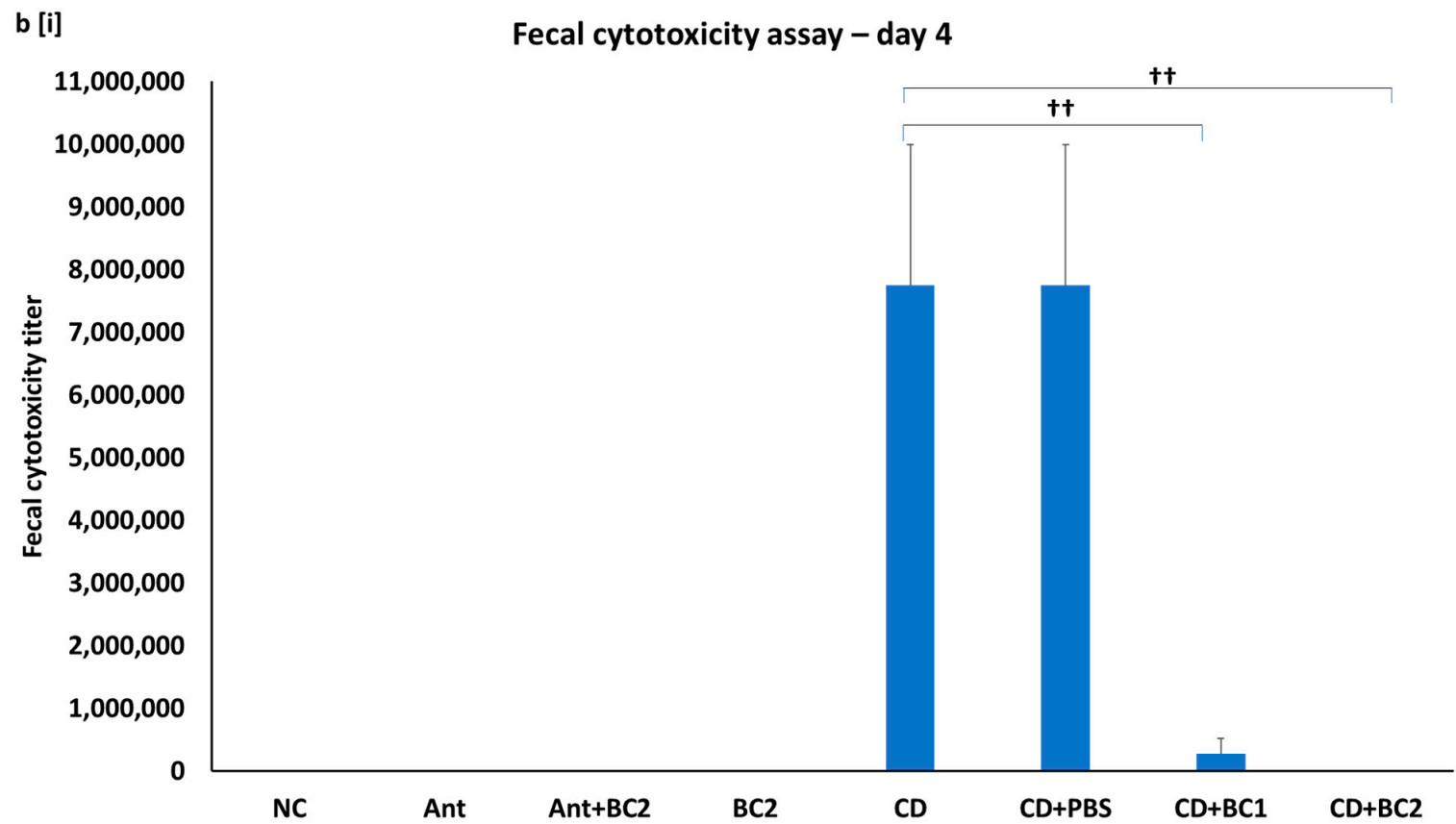

b [ii]

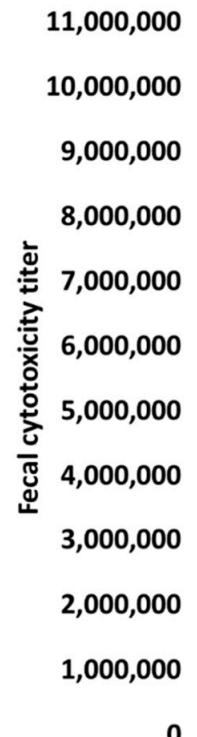

\section{Fecal cytotoxicity assay - day 6}

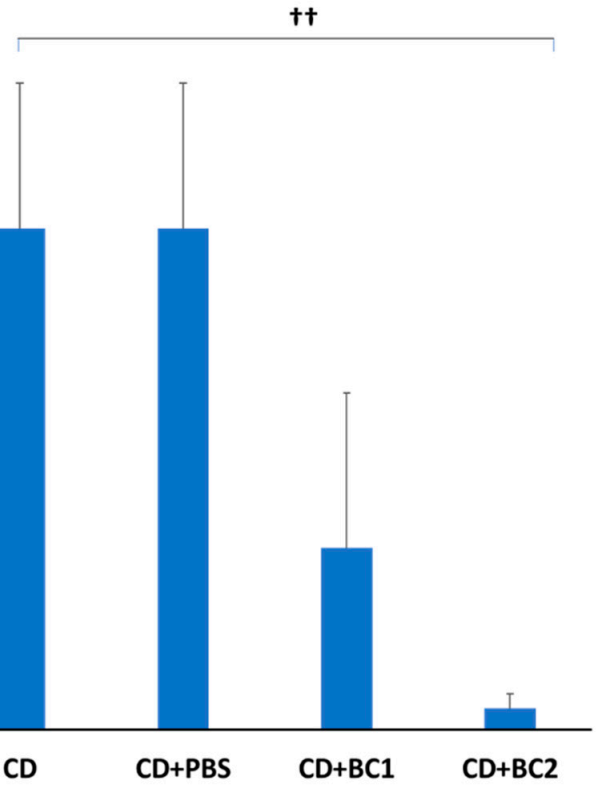

Figure 5. Effect of prophylactic baicalin supplementation on C. difficile counts and Vero cell cytotoxicity using fecal slurry supernatants. (a) Enumeration of $C$. difficile from fecal samples using (i) qPCR-based quantification using fecal DNA (5 ng content) from day 2 post infection, and (a (ii,iii)) serial dilution and plating of fecal samples on cycloserine-cefoxitin fructose containing $0.1 \%$ sodium taurocholate (CCFA-T) agar plates from day 4 and 6 post infection. (b(i,ii)) Fecal cytotoxicity assay using fecal samples collected during day 4 and 6 of the prophylactic study. Error bars represent SEM.,+++ symbol indicates a statistically significant difference $(p<0.001, p<0.05$, respectively) relative to challenged positive control (CD) vs. the baicalin-treated challenged mice $(\mathrm{CD}+\mathrm{BC} 1$ or $\mathrm{CD}+\mathrm{BC} 2)$.

\section{Discussion}

In the current study, we investigated the prophylactic and therapeutic efficacies of baicalin as an alternative agent to ameliorate CDI without compromising the normal gut microbial population. Previous research conducted in our laboratory revealed that subinhibitory concentration of baicalin reduced $C$. difficile toxin production and cytotoxicity 
in vitro. Additionally, baicalin inhibited C. difficile spore germination and outgrowth [31]. The results from the current study translate our previous findings in vivo by demonstrating a dose-dependent reduction of CDI severity in BC-supplemented mice. Concurring with the reduced incidence of diarrhea in baicalin-treated C. difficile-infected mice $(p<0.05)$ (Figure 2a,b), a significant reduction in average clinical scores, fecal toxin-mediated Vero cell cytotoxicity, and histopathologic lesion scores were also observed compared with the challenge control group (CD) $(p<0.05)$ (Figure $2 c, d$, Figures $4 b$ and $5 b)$. Although the fecal C. difficile counts on day 6 were comparable across the challenged mice groups treated with or without BC (5a (iii)), there was a significant reduction in the fecal toxin-mediated Vero cell cytotoxicity in the $\mathrm{CD}+\mathrm{BC} 2$ mouse group (Figure $5 b(\mathrm{ii})$ ). The reduced CDI severity in baicalin-treated mice could be attributed to the inhibitory effect of baicalin on C. difficile toxin production, as observed in our in vitro studies [31]. In addition, baicalin is known to possess anti-inflammatory and anti-diarrheal properties [34-36], which could also have contributed to the improved clinical outcome in BC-administered mice.

A normal and healthy gastrointestinal microbiota is key for preventing pathogen colonization, including C. difficile [37]. Disruption of host gut microbiota as a result of antibiotic therapy is the most important predisposing factor for CDI [1]. Antibiotic administration significantly alters microbiome diversity and composition, the effects of which can persist even after the withdrawal of antibiotics $[38,39]$. The increased risk for CDI susceptibility in the elderly is attributed to the reduction of the protective bacterial population such as Firmicutes and undesirable Proteobacteria groups in the gut [40-42].

In this study, baicalin did not reduce the bacterial diversity of the mouse gut microbiome compared with the untreated negative control (Figure 3c,d). Baicalin treatment alone significantly increased the abundance of Firmicutes, especially the members of Lachnospiraceae and, to a modest extent, the Lactobacillaceae group, compared with the negative control (Figure 3b). Microbiome analyses of human CDI patients by previous researchers have identified that Ruminococcaceae and Lachnospiraceae, as well as butyrate-producing bacteria were significantly depleted in patients with CDI compared with healthy subjects, whereas Enterococcus and Lactobacillus were more abundant in CDI patients [43]. In addition, a decrease in Enterococcaceae along with an increase in Peptostreptococcaceae, Lactobacillaceae, and Enterobacteriaceae have also been reported in C. difficile-positive patients [44-49]. An abundance of Lachnospiraceae, Ruminococcaceae, and Bacteroidaceae families mainly contribute to $C$. difficile colonization resistance in humans $[43,47,50]$. Similar observations in the gut microbiome of mice were also observed, wherein an increase in Lactobacillaceae and Enterobacteriaceae families was noted in susceptible mice that were treated with antibiotics, whereas Lachnospiraceae dominated in animals that remained resistant to CDI [51]. In addition, it has been collectively implicated from several research findings that that a decrease in Lachnospiraceae and Barnesiella with an increase in Lactobacillaceae and Enterobacteriaceae is responsible for the loss of colonization resistance against $C$. difficile [50]. Antibioticinduced microbiome dynamics observed in the current study are in agreement with the findings reported by previous researchers. Antibiotic pre-treatment significantly increased the abundance of the Lactobacillaceae and Proteobacteria, with a drastic reduction in the Lachnospiraceae (Figure 3b). This change in the microbial composition could be correlated with an increased susceptibility of mice to $C$. difficile challenge. Akkermansia genus (phylum Verrucomicrobia) is a strictly anaerobic, Gram-negative bacterium that has been detected in the intestine of most healthy individuals, representing $1-4 \%$ of the total microbiota, and is capable of utilizing gut-secreted mucin as a sole source of carbon and nitrogen [52,53]. The only species in this genus, Akkermansia muciniphila, has beneficial effects on metabolism and gut health by exhibiting anti-inflammatory and immunostimulant properties $[53,54]$. Recent studies have revealed that co-administration of $A$. muciniphila with polyphenols or prebiotics resulted in improvement of gut barrier function and reduced endotoxemia [55]. Although co-administration of baicalin with antibiotics (Ant+BC2) was not able to reverse the abundance of Enterobacteriaceae, a significant increase in Lachnospiraceae and Akkermansia was observed $(p<0.05)$ (Figure $3 b)$. Therefore, in the $\mathrm{CD}+\mathrm{BC} 1$ and $\mathrm{CD}+\mathrm{BC} 2$ groups, the 
microbiome shift observed during co-administration of baicalin and antibiotics may have contributed to the colonization resistance against $C$. difficile on days 2 and 4 post infection. The untreated spore-challenged mice groups (CD and CD+PBS) had invariably shown an increased abundance of Lactobacillus and Proteobacteria due to antibiotic administration, along with an increase in the abundance of Peptostreptococcaceae, the family under which the pathogenic $C$. difficile are classified [56]. However, in baicalin-treated spore challenge groups, we observed a dose-dependent increase in the abundance of Lachnospiraceae and Akkermansia, along with a significant reduction in Peptostreptococcaceae $(p<0.05)$ (Figure $3 b)$. These results suggest that the reduced clinical symptoms and infection in baicalin-treated animals could be attributed in part to the beneficial shift in the gut microbiome, especially with the improved abundance of Lachnospiraceae and Akkermansia.

\section{Materials and Methods}

\subsection{Ethics Statement, Animals, and Housing}

The study was performed with the approval of the Institutional Animal Care and Use Committee (IACUC) at the University of Connecticut, following the endorsed guidelines for animal care and use. Five- to six-week-old C57BL/ 6 mice were obtained from Charles River (Boston, MA), housed in a biohazard level II AALAC-accredited facility, and monitored for health status twice daily. Mice were provided with irradiated feed, autoclaved water, and bedding, along with $12 \mathrm{~h}$ light/dark cycles. The procedures that required animal handling (spore administration, cage changes, and sample collection) were done under a biosafety cabinet (class II) using proper personal protective equipment. Decontamination and sterilization of the biosafety cabinet was done using $10 \%$ bleach to prevent crosscontamination between experimental treatment groups. The mice were singly housed in a cage, and twelve cages were included for each treatment in each of the experiments.

\subsection{Prophylactic and Therapeutic Administration of Baicalin in a Mouse Model of C. difficile Infection}

The in vivo infection model was based on a previously established protocol with minor modifications [32]. Five- to six-week-old female animals were randomly assigned to one of the following eight treatment groups of thirteen animals each (Table 1). In the prophylactic model, animals were provided irradiated pellet feed and incorporated baicalin in drinking water containing 0,11 , and $22 \mathrm{mg} / \mathrm{L}$ of the compound for a period of twenty-two days (Supplementary Figure S1). As equated from the average daily water consumed by each mouse ( $\sim 5-7 \mathrm{~mL}$ per day), baicalin-treated water was expected to deliver approximately $250 \mathrm{mg} / \mathrm{kg}$ and $500 \mathrm{mg} / \mathrm{kg}$ of the compound per day in the 11 and $22 \mathrm{mg} / \mathrm{L}$ treatments, respectively. Previous researchers have indicated that baicalin dosage of $400 \mathrm{mg} / \mathrm{kg}$ is well tolerated by mice [57]. Subsequently, an antibiotic cocktail comprising kanamycin $(0.4 \mathrm{mg} / \mathrm{mL})$, gentamicin $(0.03 \mathrm{mg} / \mathrm{mL})$, colistin $(850 \mathrm{U} / \mathrm{mL})$, metronidazole $(0.215 \mathrm{mg} / \mathrm{mL})$, and vancomycin $(0.045 \mathrm{mg} / \mathrm{mL})$ was added in drinking water for 3 days. After antibiotic supplementation, the mice were switched back to their prior treatment regimens, and all animals in the challenge groups $(C D, C D+P B S, C D+B C 1$, and $\mathrm{CD}+\mathrm{BC} 2$ ) and the antibiotic control group (Ant) received a single intraperitoneal injection of clindamycin $(10 \mathrm{mg} / \mathrm{kg}$, with a maximum of $0.5 \mathrm{~mL} /$ mouse using a $27 \mathrm{G}$ needle and syringe) a day prior to $C$. difficile challenge. Pre-treatment of mice with antibiotics was intended to induce gastrointestinal dysbiosis and enable $C$. difficile colonization following the spore challenge. Mice proposed for $C$. difficile infection were orally administered $10^{6}$ spores (CFU) per $0.1 \mathrm{~mL}$ total volume of hypervirulent $C$. difficile ATCC BAA 1803 using a straight $18 \mathrm{G}$ gavage needle (1" shaft length) and were observed for signs of CDI, including diarrhea, wet tail, and hunched posture using a mouse clinical score sheet (Supplementary Figure S2 and Supplementary Table S1). 
Table 1. Different treatment groups used in the experiment. Abbreviations: Ant (antibiotic); CD (C. difficile); BC (baicalin); PBS (phosphate buffered saline).

\begin{tabular}{cccc}
\hline Group & Antibiotic & BC & $\begin{array}{c}\text { Spore } \\
\text { Challenge }\end{array}$ \\
\hline NC (Unchallenged negative control) & - & - & - \\
\hline Ant (Unchallenged antibiotic control) & + & - & - \\
\hline Ant+BC (Unchallenged antibiotic + 22 mg/L BC control) & + & + & - \\
\hline BC2 (Unchallenged 22 mg/L BC control) & - & + & - \\
\hline CD (Ant + C. difficile challenged control) & + & - & + \\
\hline CD+PBS (Ant + CD challenged, PBS solvent control) & + & - & + \\
\hline CD+BC1 (Ant + CD + 11 mg/L BC) & + & + & + \\
\hline CD+BC2 (Ant + CD + 22 mg/L BC) & + & + & + \\
\hline
\end{tabular}

The individual weight of each mouse was measured every day, fecal samples were collected on alternate days post infection (DPI; days 4 and 6 for the prophylactic study only), and all animals were observed twice daily for ten days for morbidity and mortality. At the end of the experiment (10th day after challenge), all animals were euthanized. In the therapeutic model, the only difference from the aforementioned procedure is that baicalin was administered from day 1 post- $C$. difficile spore challenge (1 DPI). In addition, microbiome analysis was not performed in the therapeutic study (Supplementary Figure S1).

\subsection{Histopathologic Analysis}

Colon and cecum were collected from each mouse from the prophylactic study $(n=8)$, and the tissues were fixed in $10 \%$ formalin. Formalin-fixed tissues were then embedded in paraffin, and slides were made and stained with hematoxylin and eosin. A boardcertified veterinary pathologist performed blinded histopathological analysis on all sections. Histopathologic grading was based on a scoring system reported previously [32,58]. Briefly, scoring was based on (1) epithelial tissue damage; (2) edema, congestion, and hemorrhage; and (3) neutrophil infiltration. A score of $0-4$ was assigned to each animal, with 0 denoting the absence of lesion, 1 for minimal, 2 for mild, 3 for moderate, and 4 for severe. Mean of individual category scores were calculated to provide an overall histopathologic lesion score for each mouse and then for each group.

\subsection{DNA Extraction, PCR Amplification, and Sequencing of Taxonomic Markers}

Fecal samples from day 2 post infection from all treatment groups (from eight animals per treatment group) of the prophylactic baicalin study were subjected to DNA extraction using the MoBio PowerMag Soil 96 well kit (MoBio Laboratories, Inc., Carlsbad, CA, USA), according to the manufacturer's protocol for the Eppendorf ep Motion liquid-handling robot. Quantification of DNA was performed using the Quant-iT PicoGreen kit (Invitrogen, ThermoFisher Scientific, Waltham, MA, USA), and DNA was subjected to amplification of partial bacterial $16 \mathrm{~S}$ rRNA genes (V4 region) from $30 \mathrm{ng}$ of extracted DNA as template, using 515F and 806R primers bound with Illumina adapters and dual indices ( 8 basepair golay in $3^{\prime}$ and $\left.5^{\prime}\right)[59,60]$. Amplification was performed in triplicates with the addition of $10 \mu \mathrm{g}$ BSA (New England BioLabs, Ipswich, MA, USA) using Phusion High-Fidelity PCR master mix (New England BioLabs, Ipswich, MA, USA). The reaction mixes were incubated at $95^{\circ} \mathrm{C}$ for $3.5 \mathrm{~min}$ and then subjected to PCR reaction for 30 cycles of $30 \mathrm{~s}$ at $95.0^{\circ} \mathrm{C}, 30 \mathrm{~s}$ at $50.0{ }^{\circ} \mathrm{C}$, and $90 \mathrm{~s}$ at $72.0^{\circ} \mathrm{C}$, followed by a final extension at $72.0^{\circ} \mathrm{C}$ for $1 \mathrm{~min}$. Quantification and visualization of pooled PCR products were performed using the QIAxcel DNA Fast Analysis (Qiagen, Germantown, MD, USA). DNA concentrations of the PCR products were normalized to $250-400 \mathrm{bp}$ and pooled using the QIAgility liquid handling robot. Pooled PCR products were cleaned up using the Gene Read Size Selection kit (Qiagen, Germantown, MD, USA) according to the manufacturer's protocol, and the 
cleaned pool was subjected to sequencing on MiSeq using a v2 $2 \times 250$ base pair kit (Illumina, Inc., San Diego, CA, USA).

\subsection{Sequence Analysis}

Microbiome analysis was set up as a completely randomized design with treatments done in replicates of eight. Filtering and clustering of sequences were performed using Mothur 1.36.1 based on a published protocol [60]. The operational taxonomic units (OTUs) of samples were clustered at $97 \%$ sequence similarity, and downstream analysis was done using $R$ version 3.2. The richness and evenness of sample OTUs were calculated by estimating alpha diversity using inverse Simpson diversity index, which were then analyzed using Tukey's test. Permutational multivariate analysis (PERMANOVA, adonis function, 75 permutations) was performed to analyze differences in bacterial community composition in the various treatment groups. Test for significance in alpha diversity was determined by ANOVA followed by Tukey's honest significant differences, adjusting for multiple comparisons $(p=0.05)$. NMS ordinations were run in R (v 3.3.0) using metaMDS in the vegan (v 2.3-5) package after calculating the stress scree plots to determine the number of axes required to achieve stress below 0.2, plotted using ggplot2 (v 2.1.0). In addition, the relative abundance of OTUs of major phyla, order, and genera was determined to assess the effect of treatment. Tukey's test was used to identify changes in groups of bacteria based on treatment, and the significance was detected at $p<0.05$.

\subsection{Fecal C. difficile Enumeration and Cytotoxicity Assay}

DNA extracted from day 2 post-infection fecal samples in the previous section (prophylactic study; $n=8$ ) was subjected to qPCR-based enumeration of $C$. difficile. The $\mathrm{Ct}$ values obtained were compared against the standard curve for the $t c d$ A gene of BAA 1803 . The bacterial counts for the standard curve ranged from $0.5 \log \mathrm{CFU} / \mathrm{mL}$ to $6 \log \mathrm{CFU} / \mathrm{mL}$. The trendline from the scatter plot of the standard curve generated the regression equation $y=-3.8456 x=36.4\left(R^{2}=0.9899\right)$, wherein $y$ denotes the $\mathrm{Ct}$ values of the respective samples and $x$ would provide the counts in $\log _{10}$ bacterial copy number/qPCR. Fecal material obtained from days 4 and 6 of the prophylactic study $(n=4)$ was subjected to $C$. difficile enumeration using serial dilution and plating. An amount of $15 \mathrm{mg}$ of fecal material was weighed and transferred into an Eppendorf tube containing $500 \mu \mathrm{L}$ of PBS. The samples were mixed thoroughly by vortexing and subjected to heat shock at $60^{\circ} \mathrm{C}$ for $20 \mathrm{~min}$ (in a water bath) to kill the vegetative bacteria and favor sporulation of $C$. difficile in the fecal slurry. To enumerate $C$. difficile spores, the samples were serially diluted and plated on to cycloserine-cefoxitin fructose agar containing $0.1 \%$ sodium taurocholate (CCFA-T)) and incubated in an anaerobic chamber (A35, Don Whitley Scientific Ltd., Bingley, UK) at $37^{\circ} \mathrm{C}$ for $48 \mathrm{~h}$. In addition, fecal samples collected from day 4 and 6 post infection were also subjected to Vero cell cytotoxicity. In this method, $15 \mathrm{mg}$ of fecal material was weighed and mixed thoroughly by vortexing with $200 \mu \mathrm{L}$ of sterile PBS and subsequently centrifuged at $14,000 \times \mathrm{g}$ at $4{ }^{\circ} \mathrm{C}$ for $10 \mathrm{~min}$ (samples were stored at $-80^{\circ} \mathrm{C}$ if not used immediately). The supernatants of the fecal slurry were subjected to Vero cell cytotoxicity assay [31]. Fecal slurry supernatants were serially diluted by $1: 10$ up to a dilution of $1: 100,000,000$ onto confluent Vero cell monolayers in 96-well microtiter plates. The cell culture plates were incubated in a carbon dioxide incubator $\left(5 \% \mathrm{CO}_{2}\right)$ at $37^{\circ} \mathrm{C}$ for $24 \mathrm{~h}$ and observed for cytopathic changes under an inverted microscope. Cytopathic changes were observed as Vero cell rounding, and the cytotoxicity titer was considered as the highest microtiter well dilution showing $80 \%$ cell rounding. The identified titer values were expressed as the reciprocal of the identified dilution.

\subsection{Statistical Analysis}

Data were analyzed using R and GraphPad Prism 8.4.2. Chi-squared test was used to compare diarrhea incidence rate between to different treatments. For analyzing the percentage body weight and average clinical scores, the differences between means between 
experimental groups across the days were compared by two-way mixed ANOVA using Tukey's test. For analyzing the qPCR based fecal $C$. difficile counts and fecal cytotoxicity assay, the differences between means were compared using one-way ANOVA. Percentage abundance of major family taxa in the microbiome was analyzed using one-way analysis using the Mann-Whitney test. A two-sided Cochran-Armitage test was used to compare the histopathologic lesion scores between the groups, with the Benjamini and Hochberg correction being applied to $p$ values. The statistical significance level was set at $p<0.05$. Survival curve comparisons were analyzed using the log-rank (Mantel-Cox) test.

\section{Conclusions}

The results from this study suggest that oral $\mathrm{BC}$ supplementation protects mice from antibiotic-induced gut dysbiosis and CDI. Baicalin supplementation significantly reduced the incidence of diarrhea as well as the severity of CDI clinical symptoms and enteric lesions in mice. In addition, BC favorably modulated the composition of gut microbiota without detrimentally affecting the gut microbiome diversity. However, further mechanistic and clinical investigations are warranted to validate and extrapolate these results for controlling CDI in human patients.

Supplementary Materials: The following are available online at https:/ /www.mdpi.com/article/10 .3390 / antibiotics10080926/s1, Figure S1: Antibiotic-induced murine CDI model, Figure S2: Mouse body condition chart, Table S1: Mouse clinical score sheet, Figure S3: Mouse survival curves.

Author Contributions: Conceptualization, K.V. and A.J.P.; methodology, A.J.P., S.M. and K.V.; software, A.J.P., B.O.F. and K.M.; validation, A.J.P., N.M., B.O.F. and K.M.; formal analysis, A.J.P.; investigation, A.J.P., P.G.V., D.A.K. and N.M.; resources, K.V.; data curation, A.J.P., N.M., B.O.F. and K.M.; writing—original draft preparation, A.J.P.; writing—review and editing, A.J.P., P.G.V., N.M., S.M. and K.V.; visualization, K.M. and A.J.P.; supervision, K.V.; project administration, A.J.P. and K.V.; funding acquisition, K.V. All authors have read and agreed to the published version of the manuscript.

Funding: This research was supported by the University of Connecticut, Office of Vice President for Research, under the Research Excellence Program 2019-20.

Institutional Review Board Statement: The study was approved by the Institutional Animal Care and Use Committee (IACUC) of the University of Connecticut (Protocol \#: A16-022, June 2018).

Informed Consent Statement: Not applicable.

Conflicts of Interest: The authors declare no conflict of interest.

\section{References}

1. Hookman, P.; Barkin, J.S. Clostridium difficile associated infection, diarrhea and colitis. World J. Gastroenterol. 2009, 15, 1554-1580. [CrossRef] [PubMed]

2. McFarland, L.V. Antibiotic-associated diarrhea: Epidemiology, trends and treatment. Future Microbiol. 2008, 3, 563-578. [CrossRef]

3. Weese, J.S.; Rousseau, J.; Deckert, A.; Gow, S.; Reid-Smith, R.J. Clostridium difficile and methicillin-resistant Staphylococcus aureus shedding by slaughter-age pigs. BMC Vet. Res. 2011, 7, 41. [CrossRef] [PubMed]

4. Leffler, D.A.; Lamont, J.T. Clostridium difficile infection. N. Engl. J. Med. 2015, 372, 1539-1548. [CrossRef]

5. Napolitano, L.M.; Edmiston, C.E., Jr. Clostridium difficile disease: Diagnosis, pathogenesis, and treatment update. Surgery 2017, 162, 325-348. [CrossRef]

6. Blossom, D.B.; McDonald, L.C. The challenges posed by reemerging Clostridium difficile infection. Clin. Infect. Dis. 2007, 45, 222-227. [CrossRef]

7. Spigaglia, P. Recent advances in the understanding of antibiotic resistance in Clostridium difficile infection. Ther. Adv. Infect. Dis. 2016, 3, 23-42.

8. Sunenshine, R.H.; McDonald, L.C. Clostridium difficile-associated disease: New challenges from an established pathogen. Cleve. Clin. J. Med. 2006, 73, 187-197. [CrossRef]

9. Bartlett, J.G. Antibiotic-associated diarrhea. Clin. Infect. Dis. 1992, 15, 573-581. [CrossRef]

10. Dial, S.; Delaney, J.A.; Schneider, V.; Suissa, S. Proton pump inhibitor use and risk of community-acquired Clostridium difficileassociated disease defined by prescription for oral vancomycin therapy. CMAJ 2006, 175, 745-748. [CrossRef]

11. Kelly, C.P.; LaMont, J.T. Clostridium difficile infection. Annu. Rev. Med. 1998, 49, 375-390. [CrossRef] [PubMed] 
12. Ling, Z.; Liu, X.; Jia, X.; Cheng, Y.; Luo, Y.; Yuan, L.; Wang, Y.; Zhao, C.; Guo, S.; Li, L.; et al. Impacts of infection with different toxigenic Clostridium difficile strains on faecal microbiota in children. Sci. Rep. 2014, 4, 7485. [CrossRef] [PubMed]

13. Seekatz, A.M.; Young, V.B. Clostridium difficile and the microbiota. J. Clin. Investig. 2014, 124, 4182-4189. [CrossRef] [PubMed]

14. Shahinas, D.; Silverman, M.; Sittler, T.; Chiu, C.; Kim, P.; Allen-Vercoe, E.; Weese, S.; Wong, A.; Low, D.E.; Pillai, D.R. Toward an understanding of changes in diversity associated with fecal microbiome transplantation based on 16S rRNA gene deep sequencing. MBio 2012, 3, e00338-12. [CrossRef]

15. Theriot, C.M.; Koenigsknecht, M.J.; Carlson, P.E.; Hatton, G.E.; Nelson, A.M.; Li, B.; Huffnagle, G.B.; Li, J.Z.; Young, V.B. Antibiotic-induced shifts in the mouse gut microbiome and metabolome increase susceptibility to Clostridium difficile infection. Nat. Commun. 2014, 5, 3114. [CrossRef]

16. Voth, D.E.; Ballard, J.D. Clostridium difficile toxins: Mechanism of action and role in disease. Clin. Microbiol. Rev. 2005, 18, 247-263. [CrossRef]

17. McDonald, L.C. Clostridium difficile: Responding to a new threat from an old enemy. Infect. Control Hosp. Epidemiol. 2005, 26, 672-675. [CrossRef] [PubMed]

18. McDonald, L.C.; Killgore, G.E.; Thompson, A.; Owens, R.C., Jr.; Kazakova, S.V.; Sambol, S.P.; Johnson, S.; Gerding, D.N. An epidemic, toxin gene-variant strain of Clostridium difficile. N. Engl. J. Med. 2005, 353, 2433-2441. [CrossRef]

19. Cohen, S.H.; Gerding, D.N.; Johnson, S.; Kelly, C.P.; Loo, V.G.; McDonald, L.C.; Pepin, J.; Wilcox, M.H. Clinical practice guidelines for Clostridium difficile infection in adults: 2010 update by the Society for Healthcare Epidemiology of America (SHEA) and the Infectious Diseases Society of America (IDSA). Infect. Control 2010, 31, 431-455. [CrossRef]

20. Debast, S.B.; Bauer, M.P.; Kuijper, E.J. European Society of Clinical Microbiology and Infectious Diseases: Update of the treatment guidance document for Clostridium difficile infection. Clin. Microbiol. Infect. 2014, 20, 1-26. [CrossRef]

21. Peng, Z.; Ling, L.; Stratton, C.W.; Li, C.; Polage, C.R.; Wu, B.; Tang, Y.-W. Advances in the diagnosis and treatment of Clostridium difficile infections. Emerg. Microbes Infect. 2018, 7, 15. [CrossRef]

22. US Department of Health and Human Services. Antibiotic resistance threats in the United States, 2013. Cent. Dis. Control Prev. 2013. Available online: https:/ / www.cdc.gov/drugresistance/threat-report-2013/pdf/ar-threats-2013-508.pdf (accessed on 20 March 2021).

23. Wollenweber, E. Occurrence of flavonoid aglycones in medicinal plants. Prog. Clin. Biol. Res. 1988, 280, 45-55. [PubMed]

24. Chen, Y.-C.; Shen, S.-C.; Chen, L.-G.; Lee, T.J.F.; Yang, L.-L. Wogonin, baicalin, and baicalein inhibition of inducible nitric oxide synthase and cyclooxygenase-2 gene expressions induced by nitric oxide synthase inhibitors and lipopolysaccharide. Biochem. Pharmacol. 2001, 61, 1417-1427. [CrossRef]

25. Liu, I.X.; Durham, D.G.; Richards, R.M.E. Baicalin Synergy with $\beta$-Lactam Antibiotics Against Methicillin-resistant Staphylococcus aureus and Other $\beta$-Lactam-resistant Strains of S. aureus. J. Pharm. Pharmacol. 2000, 52, 361-366. [CrossRef] [PubMed]

26. Novy, P.; Urban, J.; Leuner, O.; Vadlejch, J.; Kokoska, L. In vitro synergistic effects of baicalin with oxytetracycline and tetracycline against Staphylococcus aureus. J. Antimicrob. Chemother. 2011, 66, 1298-1300. [CrossRef]

27. Tsou, L.K.; Lara-Tejero, M.; RoseFigura, J.; Zhang, Z.J.; Wang, Y.-C.; Yount, J.S.; Lefebre, M.; Dossa, P.D.; Kato, J.; Guan, F. Antibacterial flavonoids from medicinal plants covalently inactivate type III protein secretion substrates. J. Am. Chem. Soc. 2016, 138, 2209-2218. [CrossRef]

28. Wang, H.; Liu, D. Baicalin inhibits high-mobility group box 1 release and improves survival in experimental sepsis. Shock 2014, 41, 324-330. [CrossRef]

29. Zhang, Y.; Qi, Z.; Liu, Y.; He, W.; Yang, C.; Wang, Q.; Dong, J.; Deng, X. Baicalin Protects Mice from Lethal Infection by Enterohemorrhagic Escherichia coli. Front. Microbiol. 2017, 8, 395. [CrossRef] [PubMed]

30. Zhu, J.; Wang, J.; Sheng, Y.; Zou, Y.; Bo, L.; Wang, F.; Lou, J.; Fan, X.; Bao, R.; Wu, Y. Baicalin improves survival in a murine model of polymicrobial sepsis via suppressing inflammatory response and lymphocyte apoptosis. PLoS ONE 2012, 7, e35523. [CrossRef]

31. Pellissery, A.J.; Vinayamohan, P.G.; Venkitanarayanan, K. In vitro antivirulence activity of baicalin against Clostridioides difficile. J. Med. Microbiol. 2020, 69, 631-639. [CrossRef]

32. Chen, X.; Katchar, K.; Goldsmith, J.D.; Nanthakumar, N.; Cheknis, A.; Gerding, D.N.; Kelly, C.P. A mouse model of Clostridium difficile-associated disease. Gastroenterology 2008, 135, 1984-1992. [CrossRef]

33. Sun, X.; Wang, H.; Zhang, Y.; Chen, K.; Davis, B.; Feng, H. Mouse relapse model of Clostridium difficile infection. Infect. Immun. 2011, 79, 2856-2864. [CrossRef]

34. Chen, J.; Zhang, R.; Wang, J.; Yu, P.; Liu, Q.; Zeng, D.; Song, H.; Kuang, Z. Protective effects of baicalin on LPS-induced injury in intestinal epithelial cells and intercellular tight junctions. Can. J. Physiol. Pharmacol. 2014, 93, 233-237. [CrossRef]

35. Dou, W.; Mukherjee, S.; Li, H.; Venkatesh, M.; Wang, H.; Kortagere, S.; Peleg, A.; Chilimuri, S.S.; Wang, Z.-T.; Feng, Y. Alleviation of gut inflammation by Cdx2/Pxr pathway in a mouse model of chemical colitis. PLoS ONE 2012, 7, e36075.

36. Ishimaru, K.; Nishikawa, K.; Omoto, T.; Asai, I.; Yoshihira, K.; Shimomura, K. Two flavone 2'-glucosides from Scutellaria baicalensis. Phytochemistry 1995, 40, 279-281. [CrossRef]

37. Britton, R.A.; Young, V.B. Role of the intestinal microbiota in resistance to colonization by Clostridium difficile. Gastroenterology 2014, 146, 1547-1553. [CrossRef]

38. Antonopoulos, D.A.; Huse, S.M.; Morrison, H.G.; Schmidt, T.M.; Sogin, M.L.; Young, V.B. Reproducible community dynamics of the gastrointestinal microbiota following antibiotic perturbation. Infect. Immun. 2009, 77, 2367-2375. [CrossRef] 
39. Dethlefsen, L.; Huse, S.; Sogin, M.L.; Relman, D.A. The pervasive effects of an antibiotic on the human gut microbiota, as revealed by deep 16S rRNA sequencing. PLoS Biol. 2008, 6, e280. [CrossRef]

40. Biagi, E.; Nylund, L.; Candela, M.; Ostan, R.; Bucci, L.; Pini, E.; Nikkila, J.; Monti, D.; Satokari, R.; Franceschi, C.; et al. Through ageing, and beyond: Gut microbiota and inflammatory status in seniors and centenarians. PLoS ONE 2010, 5, e10667. [CrossRef]

41. Claesson, M.J.; Cusack, S.; O’Sullivan, O.; Greene-Diniz, R.; de Weerd, H.; Flannery, E.; Marchesi, J.R.; Falush, D.; Dinan, T.; Fitzgerald, G.; et al. Composition, variability, and temporal stability of the intestinal microbiota of the elderly. Proc. Natl. Acad. Sci. USA 2011, 108, 4586-4591. [CrossRef]

42. Hopkins, M.J.; Sharp, R.; Macfarlane, G.T. Age and disease related changes in intestinal bacterial populations assessed by cell culture, 16S rRNA abundance, and community cellular fatty acid profiles. Gut 2001, 48, 198-205. [CrossRef] [PubMed]

43. Antharam, V.C.; Li, E.C.; Ishmael, A.; Sharma, A.; Mai, V.; Rand, K.H.; Wang, G.P. Intestinal dysbiosis and depletion of butyrogenic bacteria in Clostridium difficile infection and nosocomial diarrhea. J. Clin. Microbiol. 2013, 51, 2884-2892. [CrossRef]

44. Buffie, C.G.; Jarchum, I.; Equinda, M.; Lipuma, L.; Gobourne, A.; Viale, A.; Ubeda, C.; Xavier, J.; Pamer, E.G. Profound alterations of intestinal microbiota following a single dose of clindamycin results in sustained susceptibility to Clostridium difficile-induced colitis. Infect. Immun. 2012, 80, 62-73. [CrossRef] [PubMed]

45. Perez-Cobas, A.E.; Artacho, A.; Ott, S.J.; Moya, A.; Gosalbes, M.J.; Latorre, A. Structural and functional changes in the gut microbiota associated to Clostridium difficile infection. Front. Microbiol. 2014, 5, 335. [CrossRef]

46. Rea, M.C.; O'Sullivan, O.; Shanahan, F.; O'Toole, P.W.; Stanton, C.; Ross, R.P.; Hill, C. Clostridium difficile carriage in elderly subjects and associated changes in the intestinal microbiota. J. Clin. Microbiol. 2012, 50, 867-875. [CrossRef]

47. Schubert, A.M.; Rogers, M.A.; Ring, C.; Mogle, J.; Petrosino, J.P.; Young, V.B.; Aronoff, D.M.; Schloss, P.D. Microbiome data distinguish patients with Clostridium difficile infection and non-C. difficile-associated diarrhea from healthy controls. MBio 2014, 5, e01021-14. [CrossRef]

48. Skraban, J.; Dzeroski, S.; Zenko, B.; Mongus, D.; Gangl, S.; Rupnik, M. Gut microbiota patterns associated with colonization of different Clostridium difficile ribotypes. PLOS ONE 2013, 8, e58005.

49. Zhang, L.; Dong, D.; Jiang, C.; Li, Z.; Wang, X.; Peng, Y. Insight into alteration of gut microbiota in Clostridium difficile infection and asymptomatic C. difficile colonization. Anaerobe 2015, 34, 1-7. [CrossRef]

50. Schubert, A.M.; Sinani, H.; Schloss, P.D. Antibiotic-Induced Alterations of the Murine Gut Microbiota and Subsequent Effects on Colonization Resistance against Clostridium difficile. MBio 2015, 6, e00974-15. [CrossRef]

51. Reeves, A.E.; Koenigsknecht, M.J.; Bergin, I.L.; Young, V.B. Suppression of Clostridium difficile in the gastrointestinal tracts of germfree mice inoculated with a murine isolate from the family Lachnospiraceae. Infect. Immun. 2012, 80, 3786-3794. [CrossRef]

52. Collado, M.C.; Derrien, M.; Isolauri, E.; de Vos, W.M.; Salminen, S. Intestinal integrity and Akkermansia muciniphila, a mucindegrading member of the intestinal microbiota present in infants, adults, and the elderly. Appl. Environ. Microbiol. 2007, 73, 7767-7770. [CrossRef] [PubMed]

53. Derrien, M.; Van Baarlen, P.; Hooiveld, G.; Norin, E.; Muller, M.; de Vos, W. Modulation of mucosal immune response, tolerance, and proliferation in mice colonized by the mucin-degrader Akkermansia muciniphila. Front. Microbiol. 2011, 2, 166. [CrossRef] [PubMed]

54. Naito, Y.; Uchiyama, K.; Takagi, T. A next-generation beneficial microbe: Akkermansia muciniphila. J. Clin. Biochem. Nutr. 2018, 18-57. [CrossRef]

55. Anhê, F.F.; Pilon, G.; Roy, D.; Desjardins, Y.; Levy, E.; Marette, A. Triggering Akkermansia with dietary polyphenols: A new weapon to combat the metabolic syndrome? Gut Microbes 2016, 7, 146-153. [CrossRef] [PubMed]

56. Yutin, N.; Galperin, M.Y. A genomic update on clostridial phylogeny: G ram-negative spore formers and other misplaced clostridia. Environ. Microbiol. 2013, 15, 2631-2641. [PubMed]

57. Xi, Y.; Wu, M.; Li, H.; Dong, S.; Luo, E.; Gu, M.; Shen, X.; Jiang, Y.; Liu, Y.; Liu, H. Baicalin Attenuates High Fat Diet-Induced Obesity and Liver Dysfunction: Dose-Response and Potential Role of CaMKKbeta/AMPK/ACC Pathway. Cell. Physiol. Biochem. 2015, 35, 2349-2359. [CrossRef]

58. Shelby, R.D.; Tengberg, N.; Conces, M.; Olson, J.K.; Navarro, J.B.; Bailey, M.T.; Goodman, S.D.; Besner, G.E. Development of a standardized scoring system to assess a murine model of Clostridium difficile colitis. J. Investig. Surg. 2019, 33, 887-895. [CrossRef] [PubMed]

59. Caporaso, J.G.; Lauber, C.L.; Walters, W.A.; Berg-Lyons, D.; Huntley, J.; Fierer, N.; Owens, S.M.; Betley, J.; Fraser, L.; Bauer, M.; et al. Ultra-high-throughput microbial community analysis on the Illumina HiSeq and MiSeq platforms. ISME J. 2012, 6, 1621-1624. [CrossRef]

60. Kozich, J.J.; Westcott, S.L.; Baxter, N.T.; Highlander, S.K.; Schloss, P.D. Development of a dual-index sequencing strategy and curation pipeline for analyzing amplicon sequence data on the MiSeq Illumina sequencing platform. Appl. Environ. Microbiol. 2013, 79, 5112-5120. [CrossRef] 